Engineerng Research

Engineering Research

Engineering Research

Engineering Research

Enguneering Research

Engineering Research

Engineering Research

Engineering Research

by Bruce Jensen and Jeffrey Sanders

Argonne National Laboratory-West

Engineering Research

Engineering Research

Tracy Wenz

Los Alamos National Laboratory

Engineering Research

Robert Buchheit, Jr.

Engineering Research Texas A\&M University

Engineering Research

Engineering Research

Engineering Research

Fingineering Research

Engineering Research

Engineering Research

Engineerng Research

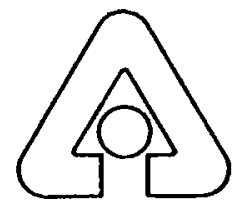

Argonne National Laboratory, Argonne, Illinois 60439

operated by The University of Chicago

for the United States Department of Energy under Contract W-31-109-Eng-38

Engineering Research Engineering Pesearch Engineering Research Englueering Research Engineering Research Engineering Research Engivesung Research Engineering Pesearch 
Argonne National Laboratory, with facilities in the states of Illinois and Idaho, is owned by the United States Government and operated by The University of Chicago under the provisions of a contract with the Department of Energy.

\section{DISCLAIMER}

This report was prepared as an account of work sponsored by an agency of the United States Government. Neither the United States Government nor any agency thereof, nor The University of Chicago, nor any of their employees or officers, makes any warranty, express or implied, or assumes any legal liability or responsibility for the accuracy, completeness, or usefulness of any information, apparatus, product, or process disclosed, or represents that its use would not infringe privately owned rights. Reference herein to any specific commercial product, process, or service by trade name, trademark, manufacturer, or otherwise, does not necessarily constitute or imply its endorsement, recommendation, or favoring by the United States Government or any agency thereof. The views and opinions of document authors expressed herein do not necessarily state or reflect those of the United States Government or any agency thereof, Argonne National Laboratory, or The University of Chicago.

Available electronically at http://www.doe.gov/bridge

Available for a processing fee to U.S. Department of Energy and its contractors, in paper, from:

U.S. Department of Energy Office of Scientific and Technical Information

P.O. Box 62

Oak Ridge, TN 37831-0062

phone: (865) 576-8401

fax: (865) 576-5728

email: reports@adonis.osti.gov 


\title{
Results of Active Well Coincidence Counter Cross-Calibration Measurements at Argonne National Laboratory-West
}

\author{
Bruce Jensen, Argonne National Laboratory-West \\ Jeffrey Sanders, Argonne National Laboratory-West \\ Tracy Wenz, Los Alamos National Laboratory \\ Robert Buchheit, Jr., Texas A\&M University
}

September 2002 


\section{Table of Contents}

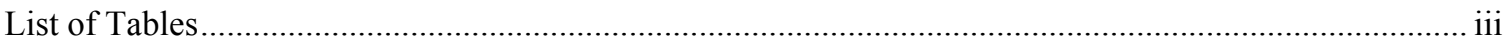

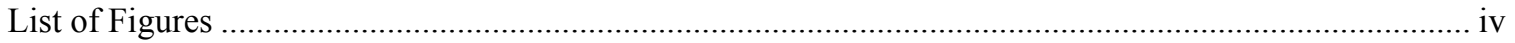

Summary

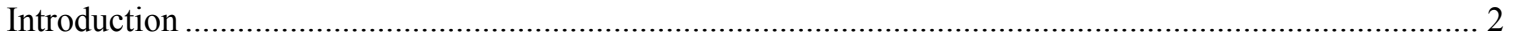

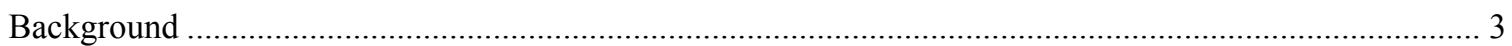

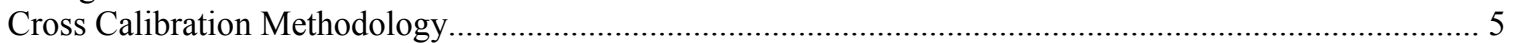

Cross Calibration Procedure for the ANLW AWCC ..................................................................... 8

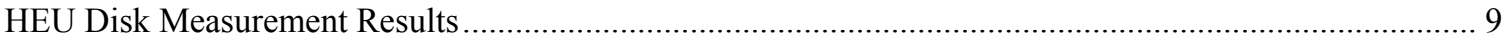

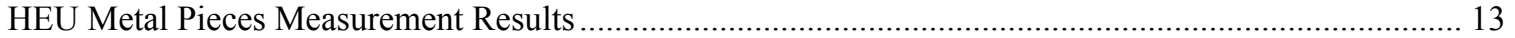

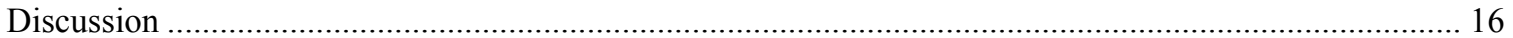

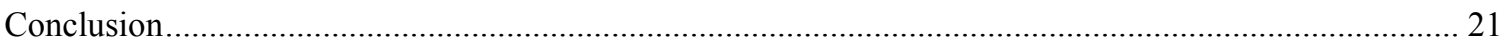

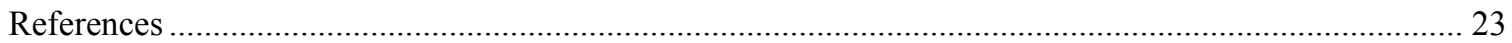

Appendix I. Draft Field Guide for Assay of HEU Metal Samples using Cross Calibration....................... 24

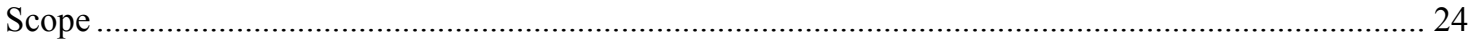

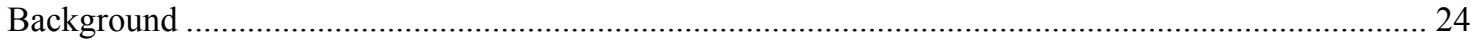

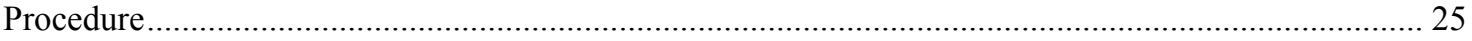

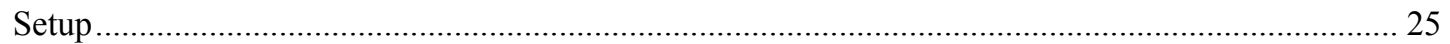

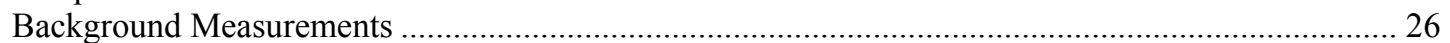

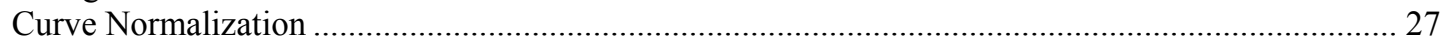

Appendix II. Russian AWCC Calibration Cross-Reference Data for HEU Metal Disks (Mode-1) ............ 28

Appendix III. AmLi Source Yield Comparison......................................................................... 30 


\section{List of Tables}

Table 1. Characteristics of the $C$-20 series HEU metal disk physical standards ...................................... 8

Table 2. Updated AWCC Calibration Cross-Reference Data .................................................................... 9

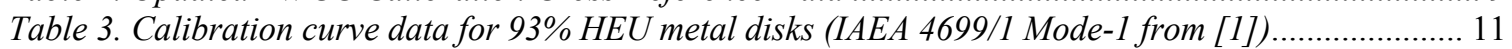

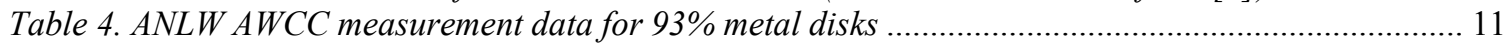

Table 5. Calibration data for 93\% HEU metal pieces (LANL/EUR SN300 Mode-I from [1]).................... 14

Table 6. ANLW AWCC measurement data of 93\% HEU heel pieces .................................................... 15

Table 7. Summary of $k_{\text {ref }}$ determined from AmLi and Cf-252 source and C-20-8 standard measurements .. 20

Table 8. Standard JSR-12 operating parameters ........................................................................... 25

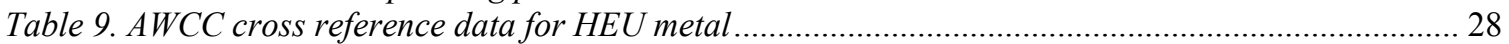

Table 10. AmLi source yield comparison ................................................................................................ 30 


\section{List of Figures}

Figure 1. Calibrations curves for 93\% HEU metal disks and pieces from LA-11229-MS ........................ 4

Figure 2. Plot of ANLW 93\% HEU metal disk data and the adjusted cross calibration curve .................. 12

Figure 3. Plot of calculated mass error for 93\% HEU disks measured with ANLW AWCC...................... 12

Figure 4. Plot of ANLW 93\% HEU metal pieces data and the adjusted LANL calibration curve .............. 14

Figure 5. Plot of calculated mass error for 93\% HEU pieces measured with ANLW AWCC.................... 15

Figure 6. Cross calibration flow chart employing AmLi sources for field system correction ..................... 17

Figure 7. Cross calibration flow chart employing AmLi sources for field system correction ..................... 18

Figure 8. Alternative calibration technique utilizing $C f-252$ source to determine field correction, LANL reference measurements to relate systems and predetermined calibration curves............................. 19

Figure 9. Error in $k_{\text {ref }}$ determined by AmLi and Cf-252 source measurements relative to reference measurements 


\section{Summary}

Over 25 active well coincidence counter systems have been supplied to Russia by the U.S. Department of Energy for the nondestructive assay of nuclear material. Due to the shortage of physical standards, few of these systems have calibration curves suitable to the material they will be assaying. To enable the calibration of these systems, a cross calibration technique developed at Los Alamos National Laboratory is being investigated as a cost effective means of transferring calibration parameters among multiple systems. Previous studies have demonstrated the use of the cross calibration technique for the assay of low enriched uranium. The purpose of this study was to demonstrate the applicability of the technique as an effective method of developing calibration parameters for the assay of highly enriched uranium and to assess the implementation of a cross calibration program in Russia.

Measurements of highly enriched uranium metal items with the Argonne National Laboratory-West active well counter were used to demonstrate the applicability of the cross calibration technique. Calibration was performed by the normalization of coincidence count rates using experimentally determined reference parameters determined via reference measurements performed at Los Alamos National Laboratory. These measurements and the cross calibration technique allow the use of calibration curves measured on reference systems to determine assay mass. 93\% enriched uranium metal disk samples with masses ranging from 250-3700g were assayed, obtaining a maximum mass error of $4.36 \%$ from the declared mass and an absolute average error of $2.22 \% \pm 1.40 \%$. Samples composed of uranium metal pieces with masses ranging from 2700-4000g were analyzed using an adjusted calibration curve, determining sample mass within $6.08 \%$ of declared mass, with an average absolute mass error of $2.31 \% \pm 1.78 \%$. The sample masses calculated for the uranium metal items meet the quality control standards of the material protection control and accounting program at Argonne National Laboratory-West. Prior to shipment, the Russian active well counters performed reference measurements at Los Alamos National Laboratory. The results of these measurements are included in the report as well as an outline of possible methods of implementing a cross calibration program in Russia. 


\section{Introduction}

Nondestructive Assay (NDA) of Nuclear Materials (NM) is a common tool used by inspectors involved in Material Protection, Control and Accounting (MPC\&A) programs, both domestically and internationally. NDA is generally used to quantify the properties of $\mathrm{NM}$, usually by determining the mass or enrichment of materials such as U-235 or Pu240. For the NDA of Highly Enriched Uranium (HEU) metal, powder or scrap samples, Active Well Coincidence Counter (AWCC) NDA systems are routinely used. These systems bombard samples with neutrons, inducing fission events. The fissile mass of the sample is determined based upon the number of coincidence neutrons detected. To obtain accurate quantitative measurements using AWCC systems it is necessary to calibrate the instruments using physical standards representative of the unknown sample to be measured. During international inspections it is both expensive and difficult to obtain the large number of physical standards necessary to accurately assay the wide range of NM present at multiple sites. To address this issue, a cross-calibration method has been developed by Los Alamos National Laboratory (LANL) allowing the transfer of calibration parameters measured to field inspection systems without the need for physical standards[1].

Argonne National Laboratory-West (ANLW) routinely uses AWCC systems as part of its MPC\&A program to verify the fissile mass of HEU items of various enrichments. In addition, ANLW is involved in a MPC\&A program initiated by the U.S. Department of Energy (DOE) to provide AWCC system support to Russia. Approximately 25 AWCCs have been delivered to Russia through this program. Before shipment to Russia, the AWCC systems measured reference standards at LANL. The results of these measurements are included in Appendix II and III. Using this data, a study of the cross calibration technique using low enriched uranium was performed by the Moscow State Engineering Physics Institute (MEPhI) with encouraging results [2,3]. The purpose of the current investigation is to demonstrate the cross calibration technique as an effective method to determine calibration parameters for the assay of HEU, as well as to assess the implementation of the technique at Russian facilities. 


\section{Background}

The ANLW AWCC and the majority of the Russian systems are the model JCC-51 AWCC system manufactured by Canberra, though Aquila KCC-51 systems have also been purchased for Russia. These AWCC systems are mainly used to perform verification measurements of HEU and plutonium samples in metallic or oxide form. While AWCC systems can be operated in either active or passive counting modes, active mode is more suited to the low spontaneous fission rate of U-235. Since the scope of this investigation is the assessment of HEU assay, the Mode-I fast-active configuration is used. In active mode, HEU samples are interrogated with neutrons from AmLi sources housed in the end plugs of the system. These sources induce fission events within the sample, spontaneously releasing multiple neutrons which are detected by He-3 detectors placed in a ring around the sample. By measuring the number of coincidence neutrons emitted from the sample it is possible to determine the number of fission events occurring in the sample. In practice, the coincidence response is dependent not only upon the number of fissionable atoms in the sample, and thus the fissile mass, but also the fissile enrichment, sample density and composition. As a result, it is necessary to take these parameters into consideration while determining the sample mass, usually by developing calibration curves using physical standards identical to the samples to be assayed.

The relationship between the response of an AWCC system and the fissile mass of the sample is commonly expressed in the form of a calibration curve. Example calibration curves for HEU metal disks and pieces are shown in Figure 1. These curves are established by the development of multiple HEU standards with known fissile masses and composition, which are then measured in AWCC systems. As can be seen in Figure 1, a plot of calibration curves for HEU metal disks and pieces, small changes in sample geometry can necessitate the use of a separate calibration curve. In the case of $93 \% \mathrm{HEU}$ metals, breaking the metal disks into small ( 100-300 g) pieces decreases selfmultiplication in the sample, lowering the measured coincidence rate by nearly $15 \%$. Calibration curves are determined by interpolating the results from measurement of physical standards. Due to sample multiplication within large masses of HEU, the 
measured coincidence rate is not linearly related to mass, requiring that the physical standards used to develop calibration curves have masses extending beyond the range of possible masses to be assayed. The requirement for standards of a large mass range combined with the desire for high accuracy along the entire mass range necessitates the use of a large number of standards to develop a single calibration curve. Standards are costly, however, and add to the amount of NM that must be maintained in inventory, increasing the attractiveness of using alternative methods to determine calibration parameters. The cross calibration technique investigated in this study allows the transfer among multiple systems of calibration parameters determined from measurements of physical standards, dramatically decreasing the number of standards required to maintain an effective AWCC NDA program.

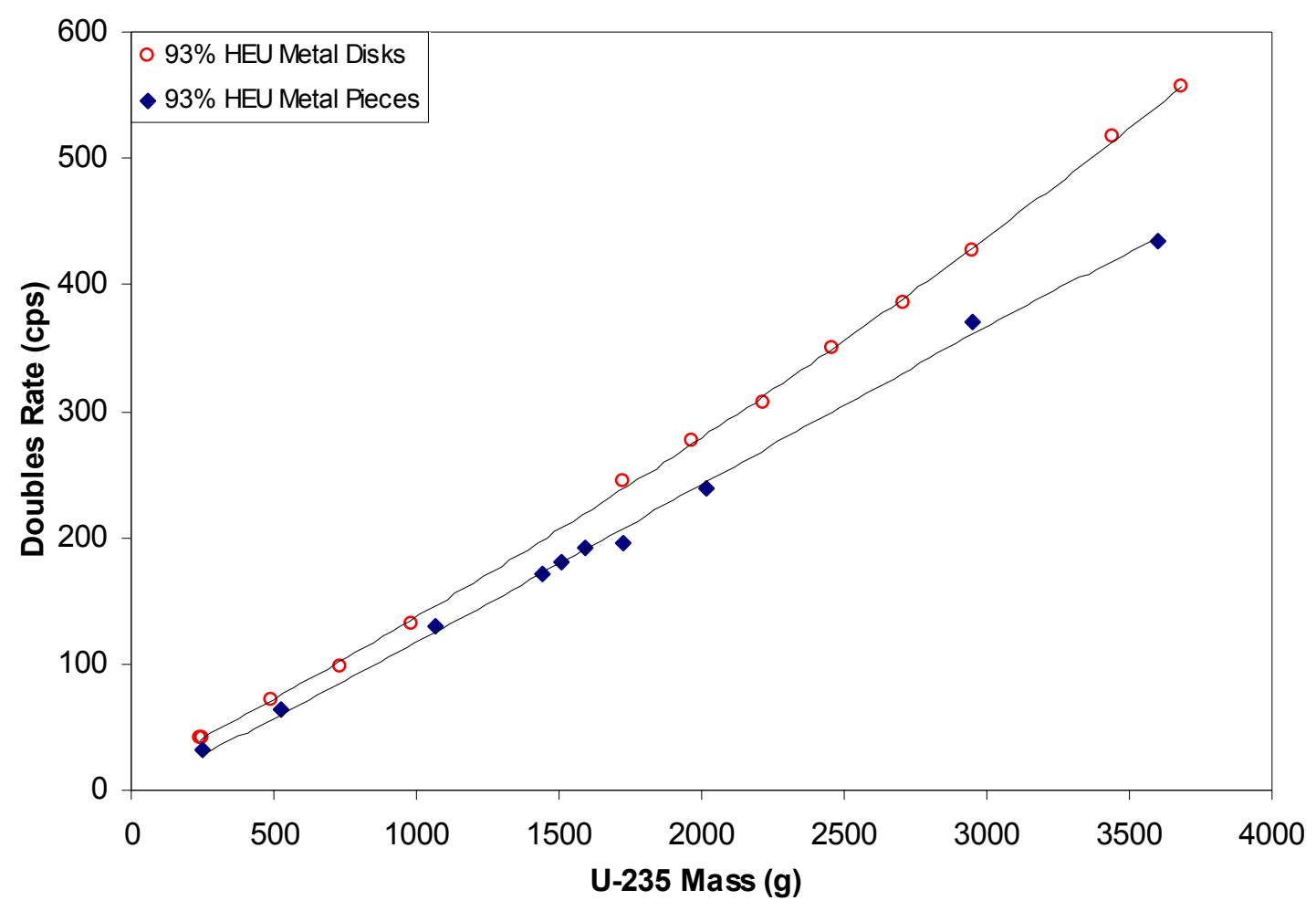

Figure 1. Calibrations curves for 93\% HEU metal disks and pieces from LA-11229-MS 


\section{Cross Calibration Methodology}

The cross calibration program outlined in this report involves the careful calibration of one reference system for a particular sample material type using physical standards. Calibration parameters determined for this reference system are then fixed and the response of other systems normalized to account for known differences in system response. The analytical basis of this calibration program is the assumption that the nonlinear shape of calibration curves are mainly characterized by sample properties and that detector related effects are nearly the same for all systems[1]. LANL initiated this cross calibration program for various types of materials and maintains the reference system, labeled as LANL/EUR SN300 and commonly referred to as AWCC-Gold. The responses of all AWCC systems involved in the cross calibration program are referenced to the AWCC-Gold system using measurements of appropriate physical standards. To account for changes in detector efficiency and electronic response during the life of the system, a Cf-252 source that remains with the field system is also measured during calibration, allowing readjustment of system normalization after the initial reference measurements are performed. In situations where a system does not have a unique Cf-252 source, the AmLi sources of the AWCC can be utilized to perform this adjustment, though with reduced accuracy. A detailed description of the calibration program is described in [1].

To implement this program, a series of normalization terms are carefully determined for each AWCC system and used to normalize field system response to that of the reference system, allowing use of predetermined reference calibration parameters. These parameters relate the coincidence rate to sample mass through a third order polynomial of the form:

$$
\begin{array}{cc}
R(m)= & \left(A_{0}+A_{1} m+A_{2} m^{2}+A_{3} m^{3}\right) / k \\
\quad \text { Or inverted as: } & \text { Eq. } 1 \\
m(k R)=a_{0}+a_{1}(k R)+a_{2}(k R)^{2}+a_{3}(k R)^{3} & \text { Eq. } 2
\end{array}
$$


where $m$ is the $\mathrm{U}-235$ mass of the sample in grams, $R$ is the measured coincidence rate and $k$ is the term used to normalize between systems. The variables $A_{0}-A_{3}$ and $a_{0^{-}} a_{3}$ are calibration parameters that depend upon the type of sample being measured. A third order polynomial is usually used to account for the self-shielding and multiplication effects that dominate the system response for highly fissile samples of extremely large mass. In practice, polynomials of first and second order may also be used for certain types of samples, though third order polynomials provide the necessary inflection point to accurately assay highly fissile samples over a wide mass range[1]. For materials with lower enrichment and density, second order polynomial curves can commonly be used[1,2].

The normalization term $k$ is mainly determined from measurements of a reference physical standard in both the field and reference system. The results of this measurement are expressed as:

$$
k_{r e f}=\frac{R_{0}(A W C C-r e f)}{R_{0}(A W C C-x)}
$$

where $R o(A W C C-r e f)$ is the coincidence rate measured by the reference system and $\operatorname{Ro}(A W C C-x x)$ is the coincidence rate measured by the field system. Because of AmLi source decay, it is necessary to adjust the response of the field system to the date of the most recent reference system measurement since the reference system response is only periodically measured. Multiplying the field system response by this normalization term effectively adjusts the response of the field system to that of the reference system.

Due to changes in the system response resulting from AmLi source decay, changes in detector or electronic efficiency as well as differences in sample container, the normalization term shown in Equation 3 often must be modified by additional normalization terms. Changes in detector efficiency and electronic response are accounted for using the relation:

$$
k_{\text {field }}=\frac{R_{0}(C f)}{R_{\text {new }}(C f)}=\left[\frac{T_{0}}{T_{\text {new }}}\right]^{2}
$$


where $R_{0}(C f)$ is the coincidence rate of the field system to a Cf-252 source at the reference measurement location, $R_{\text {new }}(C f)$ is the coincidence rate of the field system in the field measurement location, $T_{0}$ is the net single event rate measured at the reference location and $T_{\text {new }}$ is the net single event rate at the field location. The net single event rates terms are determined by subtracting the passive background rate of the system from the active background rate, measured with the sample cavity left empty and the AmLi sources in place. Since a referenced Cf-252 source is not always present during field measurements, the change in detector and electronic response is often taken into account using the net singles rate terms associated with the system. It is important to note that both $T_{\text {new }}$ and $R_{\text {new }}(C f)$ must be measured with the system in the same configuration as used during the $T_{0}$ and $R_{0}$ measurements. Further, both $T_{\text {new }}$ and $R_{\text {new }}(C f)$ must be adjusted to account for the decay of the AmLi and Cf-252 sources since the date of calibration.

Adjusting the raw field system response by $k=k_{r e f} \mathrm{x} k_{\text {field }}$ adjusts it to that of the reference system at the date and location of calibration. Since the calibration parameters are usually determined at an earlier date, it is often necessary to further adjust the field system response to account for the decay of the AmLi sources using:

$$
k_{\text {decay }}=e^{\left(T \times \ln 2 / T_{1 / 2}\right)}
$$

where $\mathrm{T}_{1 / 2}$ is the half-life of the AmLi source and $\mathrm{T}$ is the number of years between the calibration parameter measurement and the current field measurement. While it is also possible to correct the reference system response for source decay (to the date of field system calibration), this makes calibration amongst more than two systems difficult. Known biases due to container or geometric differences can also be accounted for using a normalization term, usually determined from measurement or simulation.

It is important to note that the normalization term $k$ can be determined using a number of methods employing measurements of various reference material and sources. One alternative method is to estimate $k_{\text {ref }}$ with the product of relative AmLi and Cf source strength measurements. These measurements are performed in passive Mode-I configuration and give an indication of both the interrogation source strength and 
detection efficiency without the need for a reference standard. Since the placement of the AmLi source within the well during source measurement and end caps during material assay as well as the distribution of the americium oxide in the sources vary, altering the $k_{r e f}$ determined using this method, it is in practice not as accurate as measurements using a reference standard [2]. Isotopes with high spontaneous fission probabilities can be substituted for the $\mathrm{Cf}-252$ source, providing a more accurate estimate of $k_{\text {field }}$ than determined using the total singles rates

\section{Cross Calibration Procedure for the ANLW AWCC}

ANLW routinely measures items of $93 \%$ HEU metal in various forms as part of its MPC\&A program. The current focus of this program is the assay of 93\% HEU metal "heels", in both solid and pieces form. For materials of this form and composition physical standards from the C-20 series of HEU metal disks, which are maintained at LANL, are used to perform reference measurements. The characteristics of these disks are shown in Table 1.

Table 1. Characteristics of the C-20 series HEU metal disk physical standards

\begin{tabular}{|c|c|c|c|c|c|c|c|c|}
\hline Disk ID & $\begin{array}{c}\text { Disk } \\
\text { Mass }\end{array}$ & $\begin{array}{c}\text { U-235 } \\
\text { Enrichment }\end{array}$ & $\begin{array}{c}\text { Uranium } \\
\text { Mass }\end{array}$ & $\begin{array}{c}\text { U-235 } \\
\text { Mass }\end{array}$ & $\begin{array}{c}\text { Disk } \\
\text { Volume }\end{array}$ & $\begin{array}{c}\text { Disk } \\
\text { Density }\end{array}$ & $\begin{array}{c}\text { Uranium } \\
\text { Density }\end{array}$ & $\begin{array}{c}\text { U-235 } \\
\text { Density }\end{array}$ \\
\hline \# & grams & $\%$ & grams & grams & $\mathrm{cm}^{3}$ & $\mathrm{~g}^{3} \mathrm{~cm}^{3}$ & $\mathrm{~g} / \mathrm{cm}^{3}$ & $\mathrm{~g} / \mathrm{cm}^{3}$ \\
\hline C-20-1 & 536.48 & $93.17 \%$ & 527.73 & 491.69 & 28.27 & 18.97 & 18.66 & 17.40 \\
\hline C-20-2 & 537.49 & $93.17 \%$ & 527.21 & 491.20 & 28.27 & 19.01 & 18.65 & 17.37 \\
\hline C-20-3 & 537.61 & $93.17 \%$ & 528.30 & 492.22 & 28.27 & 19.01 & 18.68 & 17.41 \\
\hline C-20-4 & 535.86 & $93.17 \%$ & 528.32 & 494.24 & 28.27 & 18.95 & 18.69 & 17.48 \\
\hline C-20-5 & 538.75 & $93.17 \%$ & 528.86 & 492.74 & 28.27 & 19.05 & 18.70 & 17.43 \\
\hline C-20-6 & 536.16 & $93.17 \%$ & 527.58 & 491.55 & 28.27 & 18.96 & 18.66 & 17.39 \\
\hline C-20-7 & 531.72 & $93.17 \%$ & 523.84 & 488.06 & 28.27 & 18.81 & 18.53 & 17.26 \\
\hline C-20-8 & 270.86 & $93.17 \%$ & 264.33 & 246.28 & 14.14 & 19.16 & 18.69 & 17.42 \\
\hline C-20-9 & 269.51 & $93.17 \%$ & 262.27 & 244.36 & 14.14 & 19.06 & 18.55 & 17.28 \\
\hline
\end{tabular}

The C-20-8 disk has been chosen as the reference physical standard for 93\% HEU metals and has been carefully measured with the AWCC-Gold reference system and all systems involved in the program. 
To demonstrate the applicability of the cross calibration technique to the assay of HEU, the ANLW AWCC was shipped to LANL so that reference measurements of the C-20-8 standard and reference Cf-252 source could be performed. Results from these measurements were added to Table V of LA-11229-MS[1] and are shown in Table 2 along with reference calibration data from the AWCC-Gold and IAEA-4699/1 systems. The calibration parameters for HEU metal pieces and disks are measured on the AWCCGold and IAEA-4699/1 systems, respectively, and so the reference calibration data from these systems are needed to adjust the 93\% HEU metal disk and pieces calibration curves to the ANLW AWCC system. The ANLW AWCC does not have a referenced Cf-252 source, so the total net singles rates were used to quantify changes in electronic response, as shown in Equation 4.

Table 2. Updated AWCC Calibration Cross-Reference Data

\begin{tabular}{|c|c|c|c|c|c|c|}
\hline \multicolumn{7}{|c|}{$\begin{array}{c}\text { AWCC Calibration Cross-Reference Data for HEU Metal Disks (Mode-1) } \\
\text { (truncated version of Table V from LA-11229-MS [1] }\end{array}$} \\
\hline \hline Detector ID & $\begin{array}{c}\text { AmLi } \\
(\text { Top/Bottom })\end{array}$ & $\begin{array}{c}T o(\mathrm{empty}) \\
(\mathrm{cps}) \\
(\mathrm{y}-\mathrm{m}-\mathrm{d})\end{array}$ & $\begin{array}{c}\mathrm{Cf} \\
\text { ID }\end{array}$ & $\begin{array}{c}R o(\mathrm{Cf}) \\
(\mathrm{cps})\end{array}$ & $\begin{array}{c}R o(\mathrm{XX})^{c} \\
(\mathrm{cps})\end{array}$ & $\frac{R o(\mathrm{SN} 300)}{R o(\mathrm{XX})}$ \\
\hline LANL/EUR, SN300 & MRC-116/MRC-115 & $\begin{array}{c}7128 \\
(96-03-21)\end{array}$ & CF-5 & 3052 & 41.66 & 1.000 \\
\hline $\begin{array}{c}\text { IAEA-4699/1, } \\
\text { AMPTEK }\end{array}$ & MRC-114/MRC-113 & $\begin{array}{c}\sim 6350 \\
(85-08-10)\end{array}$ & CF-5 & 3012 & 42.20 & 1.004 \\
\hline ANL-W Canberra & N059/N060 & $\begin{array}{c}5645 \\
(02-06-06)\end{array}$ & CF-5 & 2829 & 38.60 & 1.079 \\
\hline
\end{tabular}

${ }^{a}$ Mode-1 with the lids of both AmLi sources pointed away from the sample cavity.

$b_{\text {The }} R o$ (Cf) was measured with the end plugs in Mode-1, and the ${ }^{252} \mathrm{Cf}$ source $10 \mathrm{~cm}$ above the bottom (centered). Ro (Cf) is corrected for Cf- 252 decay back to $96 / 03 / 21$ using a decay constant of $\lambda=0.26196 \mathrm{y}^{-1}$.

${ }^{c}$ The $\operatorname{Ro}(\mathrm{XX})$ is corrected for AmLi source decay back to 96/03/21 using a decay constant of $\lambda=0.0016 \mathrm{y}^{-1}$.

\section{HEU Disk Measurement Results}

The first test of the ANLW AWCC calibration was to measure the C-20 series of HEU metal disks. The IAEA 4699/1 reference system was used to develop the 93\% HEU metal disk calibration curve during the initial testing of the technique. Since all systems involved in this calibration program are referenced to the AWCC-Gold system, it was necessary to first normalize the ANLW AWCC response to the AWCC-Gold system and then to the IAEA 4699/1 system, taking into account the differences in calibration date. 
The HEU disk calibration parameters are shown in Table 3. The combined normalization term:

$$
k=k_{\text {field }} \times k_{\text {decay }} \times k_{\text {ref Gold }} \times k_{\text {ref IAEA }}
$$

was used to account for the change in system response due to the location change and adjustment to the IAEA 4699/1 curve, where $k_{\text {ref }}$ old is the adjustment of the ANLW AWCC response to the AWCC-Gold system and krefIAEA is the adjustment of the AWCCGold response to the IAEA AWCC system. To adjust the calibration curve to the ANLW AWCC system, this normalization term was applied to Equation 2 using the coefficients for the HEU metal disk calibration curve measured on the IAEA 4699/1 system. The normalization reference measurement data used to translate the ANLW and IAEA AWCCs to the AWCC-Gold system were adjusted to the last date of AWCC-Gold reference calibration, 21 March, 1996. To account for the decay of the ANLW AWCC AmLi sources, the time between the generation of the HEU disk calibration curve (10 August, 1985) and the date of measurement (06 June, 2002) was used in equation 5 to determine $k_{\text {decay }}$. The ANLW AWCC was used to measure the disk standards in a location at LANL with much larger background level than present during the reference C-20-8 disk measurement. In the new location, $T_{n e w}$ was measured to be $5820 \mathrm{cps}$, roughly $3 \%$ higher than measured during the C-20-8 calibration measurement.

The masses calculated using this adjusted curve are within $5 \%$ of the declared standard mass over the applicable range of the curve and have an absolute average error of $2.22 \%$ $\pm 1.40 \%$, as shown in Table 4 and Figures $2-3$. It is important to note that while the AWCC-Gold system is used as a reference system, calibration curves generated on any system involved in the program can be translated to field systems, as demonstrated with this measurement. Specifically, this measurement demonstrates the ability of this cross calibration technique to be applied to the assay of HEU across multiple systems with different calibration dates. 
Table 3. Calibration curve data for 93\% HEU metal disks (IAEA 4699/1 Mode-1 from [1])

\begin{tabular}{|c|r|rrr|}
\hline Disk ID & \multicolumn{1}{|c|}{$\begin{array}{c}\text { U-235 } \\
\text { mass }\end{array}$} & \multicolumn{3}{|c|}{$\begin{array}{c}\text { Doubles Rate } \\
\text { (as of 85-8-10) }\end{array}$} \\
\hline$\#$ & \multicolumn{1}{|c|}{ grams } & \multicolumn{3}{|c|}{ cps } \\
\hline C-20-8 & 246.28 & 42.2 & \pm & 1.1 \\
\hline C-20-9 & 244.4 & 41.7 & \pm & 2.0 \\
\hline- & 491.7 & 70.6 & \pm & 3.0 \\
\hline- & 735.6 & 98.4 & \pm & 2.7 \\
\hline- & 983 & 132.5 & \pm & 2.7 \\
\hline- & 1722 & 245.3 & \pm & 2.8 \\
\hline- & 1967 & 276.9 & \pm & 3.5 \\
\hline C-20-1-4,9 & 2215 & 307.3 & \pm & 3.6 \\
\hline- & 2460 & 350.4 & \pm & 4.4 \\
\hline- & 2706 & 386.0 & \pm & 3.6 \\
\hline- & 2952 & 427.3 & \pm & 4.5 \\
\hline- & 3440 & 517.0 & \pm & 2.4 \\
\hline C-20-1-7,9 & 3686 & 556.1 & \pm & 4.7 \\
\hline
\end{tabular}

\begin{tabular}{|c|c|c|}
\hline $\begin{array}{r}93 \% \text { HEU Metal } \\
\text { Curve Parameters } \\
\quad 240 \leq \mathrm{m} \leq 37\end{array}$ & & $\begin{array}{l}\text { alibration } \\
\text { A-4699/1 } \\
-235\end{array}$ \\
\hline-108.40 & \pm & $1.9 \mathrm{E}+01$ \\
\hline 8.711 & \pm & 3.7E-01 \\
\hline -4.67E-03 & \pm & $1.6 \mathrm{E}-03$ \\
\hline $2.15 \mathrm{E}-06$ & \pm & $1.8 \mathrm{E}-06$ \\
\hline
\end{tabular}

Table 4. ANLW AWCC measurement data for 93\% metal disks

\begin{tabular}{|c|c|c|c|c|c|c|}
\hline \multirow{2}{*}{ Disk ID } & \multicolumn{2}{|c|}{$\begin{array}{c}\text { Declared } \\
\text { U-235 mass }\end{array}$} & \multicolumn{2}{c|}{$\begin{array}{c}\text { Doubles Rate, D } \\
\text { (background corrected) }\end{array}$} & \multicolumn{2}{c|}{$\begin{array}{c}\text { Calculated Mass from } \\
\text { Cross Calibration } \\
(\mathrm{k}=1.02632)\end{array}$} \\
\hline$\#$ & grams & $\sigma_{\mathrm{m}} / \mathrm{m}$ & $\mathrm{cps}$ & $+/-$ & grams & mass error \\
\hline C-20-9 & 244.38 & $0.82 \%$ & 39.76 & 3.79 & 239.47 & $-2.01 \%$ \\
\hline C-20-1,2,9 & 1227.46 & - & 163.59 & 3.49 & 1232.75 & $0.43 \%$ \\
\hline C-20-1-4,9 & 2213.92 & $0.16 \%$ & 310.25 & 4.52 & 2261.39 & $2.14 \%$ \\
\hline C-20-1-6,9 & 3198.21 & - & 485.28 & 5.63 & 3337.55 & $4.36 \%$ \\
\hline C-20-1-7,9 & 3686.27 & $0.13 \%$ & 560.34 & 6.30 & 3765.78 & $2.16 \%$ \\
\hline
\end{tabular}




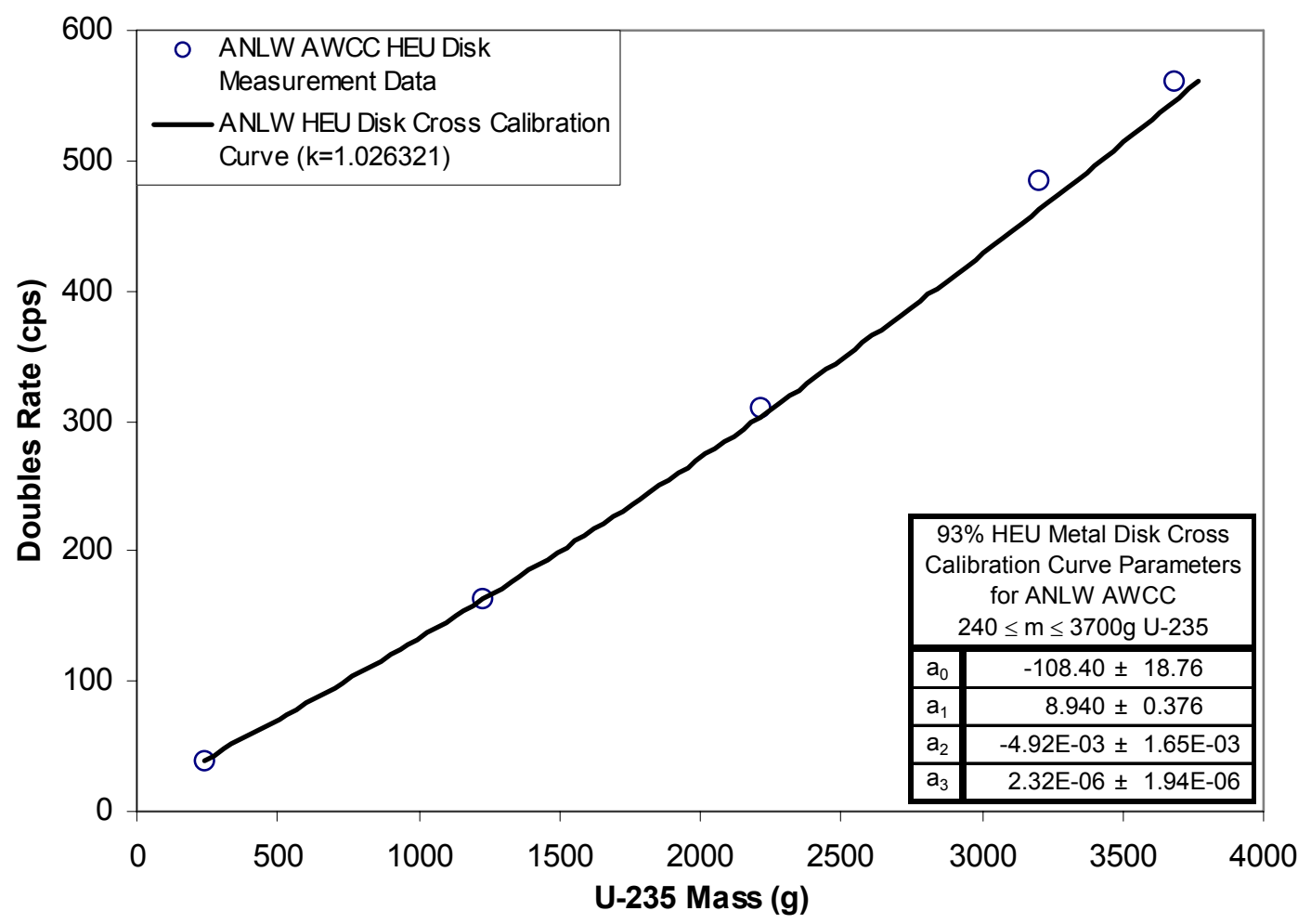

Figure 2. Plot of ANLW 93\% HEU metal disk data and the adjusted cross calibration curve

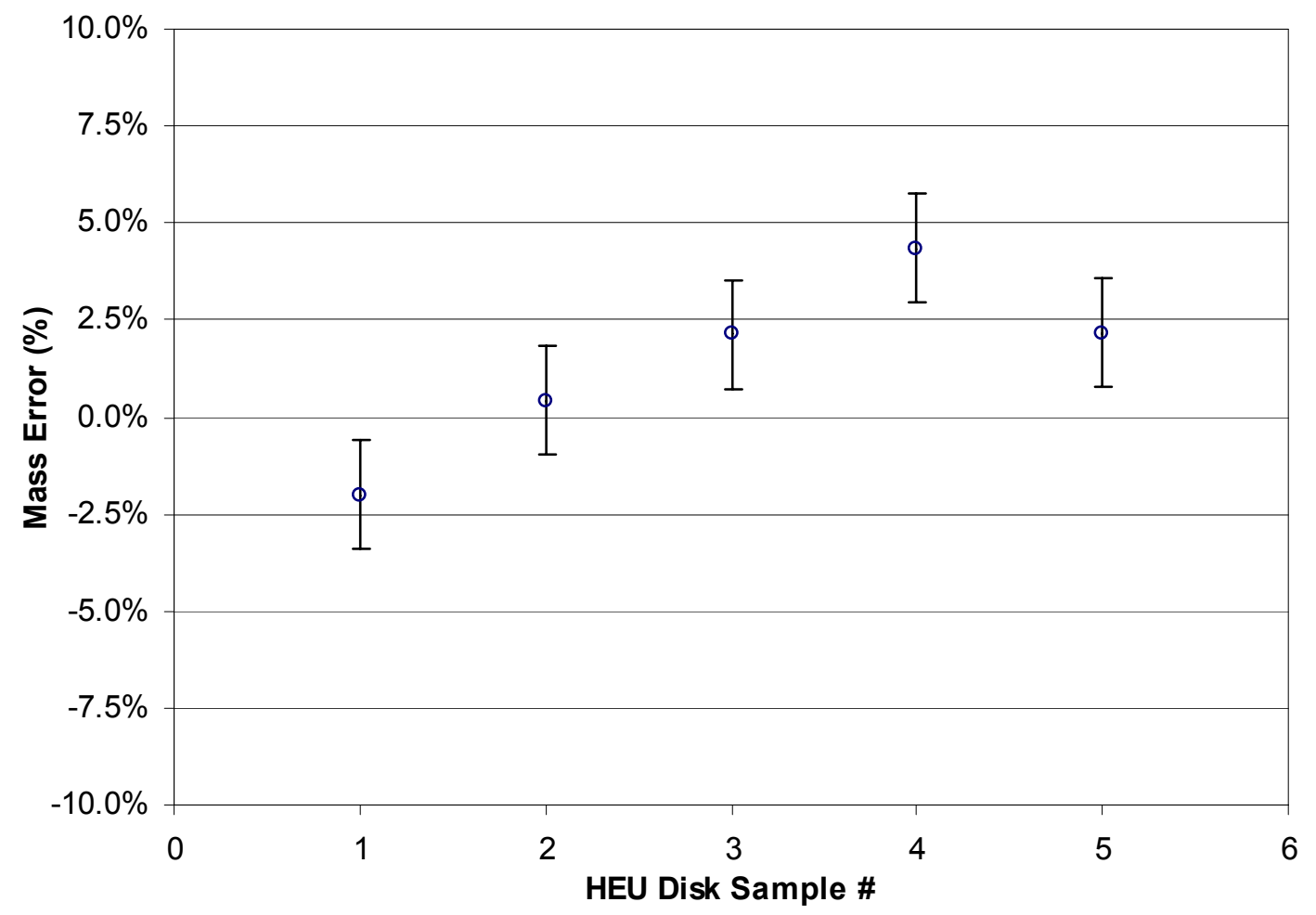

Figure 3. Plot of calculated mass error for 93\% HEU disks measured with ANLW AWCC (error bars shown are one standard deviation) 


\section{HEU Metal Pieces Measurement Results}

In addition to HEU metal in solid form, HEU metal pieces are routinely measured at ANLW as part of ongoing verification measurement programs. Samples called "heel pieces" compose a major source of HEU metal assayed at ANLW. These heel pieces are HEU metal ranging in mass from 100-300g, broken off of the larger solid heel piece. The pieces are placed in a container suitable for assay in the AWCC. Calibration parameters for the measurement of HEU metal pieces were obtained using the AWCC-Gold system and are shown in Table 5. The normalization term used is shown below.

$$
k=k_{\text {field }} \times k_{\text {ref Gold }}
$$

Since the measurements were performed over the course of two years, the ANLW system response for each measurement was decay corrected to the date the calibration curve was measured, 6 June, 1987 allowing $k_{\text {decay }}$ to be neglected in Equation 7 . The $T_{\text {new }}$ rate measured at the ANLW measurement location was on average $5885 \mathrm{cps}$ over the data collection period, determined through analysis of historic background measurements. The normalization term determined in Equation 7 and the calibration curve parameters shown in Table 5 were used to develop an adjusted calibration curve. As shown in Figure 4-5, this curve agrees well with the measured data and produces an average absolute mass error of $2.34 \% \pm 1.78 \%$, while the largest mass error was $6.08 \%$. The AWCC measurements of metal pieces were taken at ANLW, verifying that the cross calibration technique can be used to assay HEU items on systems at multiple locations with varying background levels.

It is important to note that the U-235 masses of the samples assayed at ANLW were obtained independent of AWCC measurements from detailed knowledge of the fuel manufacturing processing conditions in conjunction with mass spectroscopy and chemical analysis. From periodic mass spectroscopic and chemical analysis performed on samples, the declared mass is known within .5-1\%. This additional error combined with the statistical uncertainty in the net singles rate measurements is the reason the HEU pieces measurements have larger errors than found with the HEU disk measurements. 
Table 5. Calibration data for 93\% HEU metal pieces (LANL/EUR SN300 Mode-I from [1])

\begin{tabular}{|r|ccc|}
\hline $\begin{array}{c}\text { U-235 } \\
\text { mass }\end{array}$ & \multicolumn{3}{|c|}{$\begin{array}{c}\text { Doubles Rate } \\
\text { (as of 87-6-6) }\end{array}$} \\
\hline grams & \multicolumn{3}{|c|}{ cps } \\
\hline 250 & $31.6^{*}$ & \pm & - \\
\hline 524 & $64.6^{*}$ & \pm & - \\
\hline 1067 & 130.5 & \pm & 2.6 \\
\hline 1438 & 171.1 & \pm & 1.6 \\
\hline 1510 & 181.0 & \pm & 1.3 \\
\hline 1591 & 191.1 & \pm & 3.8 \\
\hline 1722 & 195.9 & \pm & 2.3 \\
\hline 2013 & 239.8 & \pm & 4.8 \\
\hline 2948 & 371.1 & \pm & 2.7 \\
\hline 3604 & 433.6 & \pm & 8.7 \\
\hline
\end{tabular}

\begin{tabular}{|c|c|c|c|}
\hline \multicolumn{4}{|c|}{$\begin{array}{c}\text { 93\% HEU Metal Pieces } \\
\text { Calibration Curve Parameters } \\
\text { (LANL/EUR SN300) } \\
500 \leq \mathrm{m} \leq 4000 \mathrm{~g} \mathrm{U-235}\end{array}$} \\
\hline$a_{0}$ & 0.00 & \pm & 0.0 \\
\hline$a_{1}$ & 8.117 & \pm & 4.2E-01 \\
\hline$a_{2}$ & 3.39E-03 & \pm & $3.5 E-03$ \\
\hline$a_{3}$ & $-9.35 E-06$ & \pm & 2.6E-06 \\
\hline
\end{tabular}

* indicates calculated value

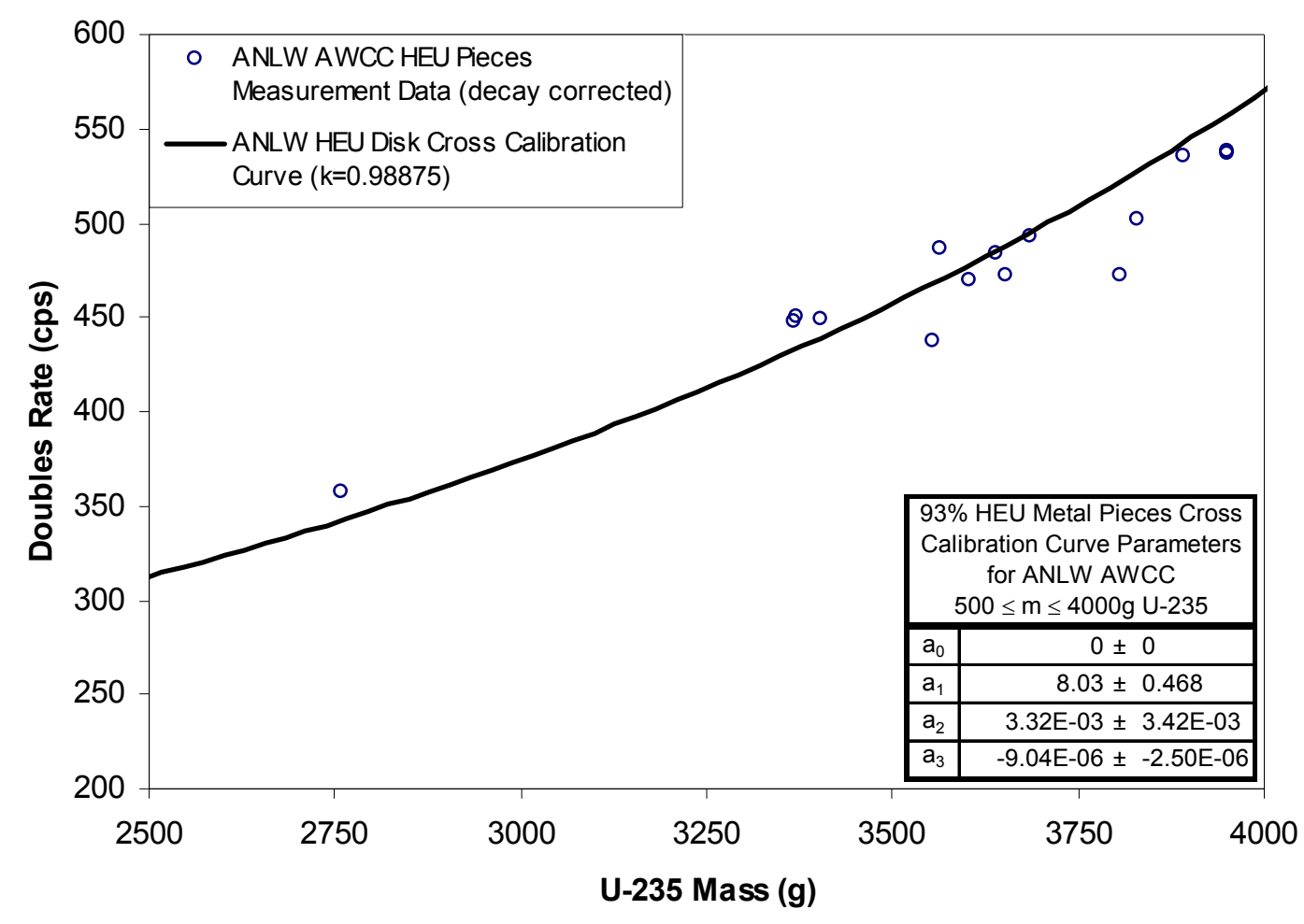

Figure 4. Plot of ANLW 93\% HEU metal pieces data and the adjusted LANL calibration curve 


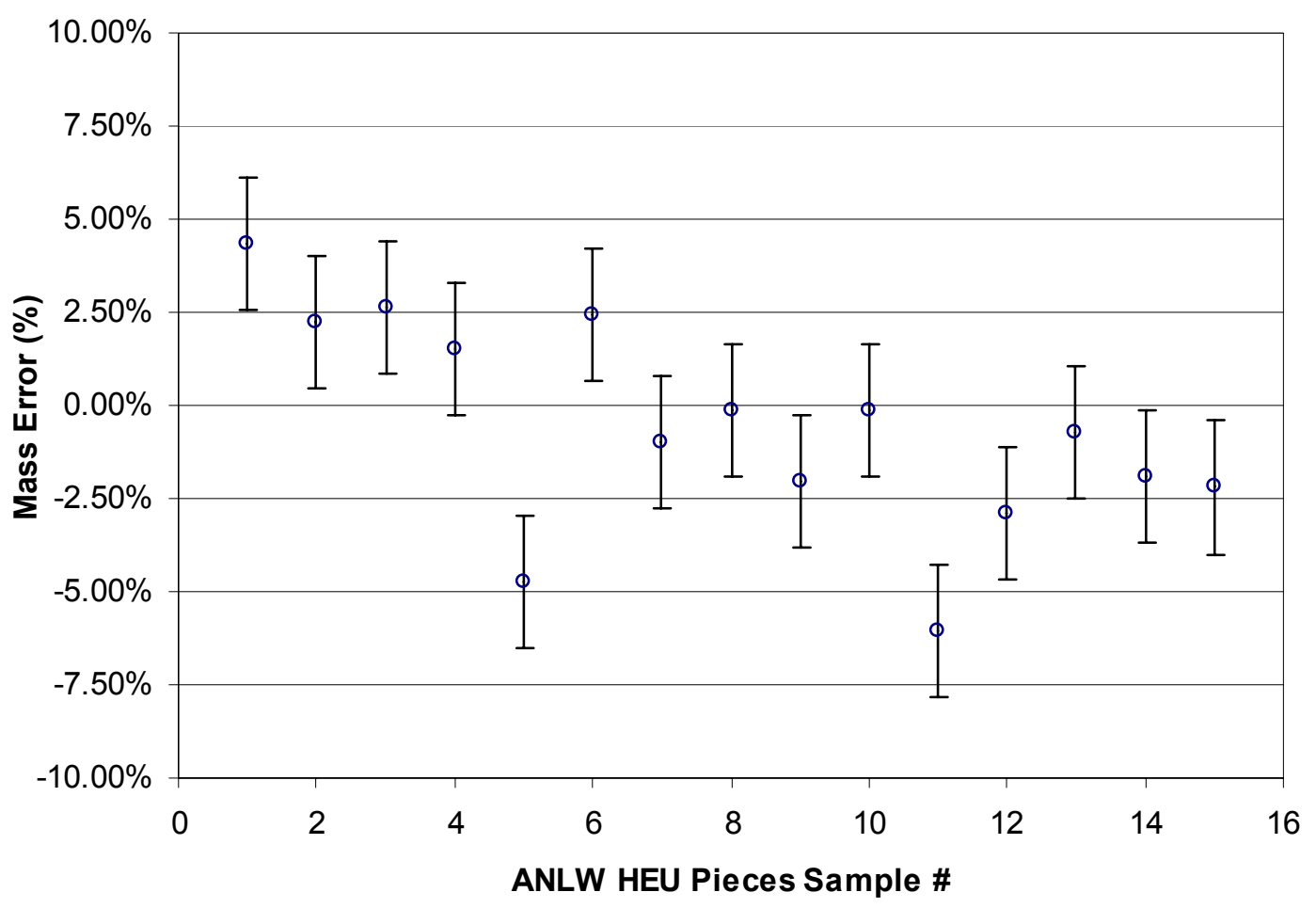

Figure 5. Plot of calculated mass error for 93\% HEU pieces measured with ANLW AWCC (error bars shown are one standard deviation)

Table 6. ANLW AWCC measurement data of $93 \%$ HEU heel pieces

\begin{tabular}{|c|c|c|c|c|c|c|c|c|}
\hline \multirow{2}{*}{ Sample ID } & \multicolumn{2}{|c|}{ Declared U-235 mass } & \multicolumn{2}{|c|}{$\begin{array}{c}\text { Doubles Rate, D } \\
\text { (background corrected) }\end{array}$} & \multicolumn{2}{c|}{$\begin{array}{c}\text { Doubles Rate, D } \\
\text { (decay corrected to 87-6-6) }\end{array}$} & \multicolumn{2}{c|}{$\begin{array}{c}\text { Calculated Mass From } \\
\text { ANW Cross Calibration } \\
\text { Curve (k=0.988751) }\end{array}$} \\
\hline \# & grams & $\sigma_{\mathrm{m}} / \mathrm{m}$ & $\mathrm{cps}$ & $+/-$ & $\mathrm{cps}$ & $+/-$ & grams & Mass Error \\
\hline ANLW1 & 2758.99 & $.5-1 \%$ & 349.35 & 4.00 & 357.41 & 4.19 & 2879.55 & $4.37 \%$ \\
\hline ANLW2 & 3368.48 & $.5-1 \%$ & 437.10 & 3.58 & 447.14 & 3.74 & 3443.79 & $2.24 \%$ \\
\hline ANLW3 & 3372.51 & $.5-1 \%$ & 433.97 & 4.18 & 450.28 & 3.78 & 3461.19 & $2.63 \%$ \\
\hline ANLW4 & 3404.87 & $.5-1 \%$ & 439.47 & 3.60 & 449.56 & 3.77 & 3457.23 & $1.54 \%$ \\
\hline ANLW5 & 3554.34 & $.5-1 \%$ & 427.10 & 4.57 & 436.90 & 4.79 & 3385.83 & $-4.74 \%$ \\
\hline ANLW6 & 3563.10 & $.5-1 \%$ & 461.32 & 3.63 & 486.76 & 3.83 & 3650.16 & $2.44 \%$ \\
\hline ANLW7 & 3602.44 & $.5-1 \%$ & 458.80 & 4.24 & 470.07 & 4.45 & 3566.83 & $-0.99 \%$ \\
\hline ANLW8 & 3639.22 & $.5-1 \%$ & 471.89 & 4.27 & 483.49 & 4.48 & 3634.28 & $-0.14 \%$ \\
\hline ANLW9 & 3653.27 & $.5-1 \%$ & 461.13 & 4.25 & 472.42 & 4.46 & 3578.90 & $-2.04 \%$ \\
\hline ANLW10 & 3687.10 & $.5-1 \%$ & 481.66 & 4.29 & 493.49 & 4.50 & 3682.24 & $-0.13 \%$ \\
\hline ANLW11 & 3807.57 & $.5-1 \%$ & 461.29 & 4.66 & 471.87 & 4.88 & 3576.05 & $-6.08 \%$ \\
\hline ANLW12 & 3830.84 & $.5-1 \%$ & 489.65 & 4.32 & 501.64 & 4.54 & 3719.82 & $-2.90 \%$ \\
\hline ANLW13 & 3890.58 & $.5-1 \%$ & 523.13 & 4.36 & 535.95 & 4.58 & 3862.82 & $-0.71 \%$ \\
\hline ANLW14 & 3949.51 & $.5-1 \%$ & 525.79 & 4.37 & 538.68 & 4.59 & 3873.08 & $-1.94 \%$ \\
\hline ANLW15 & 3950.93 & $.5-1 \%$ & 523.36 & 4.38 & 536.24 & 4.59 & 3863.90 & $-2.20 \%$ \\
\hline
\end{tabular}




\section{Discussion}

The cross calibration study performed with the ANLW AWCC demonstrates the effectiveness of the cross calibration technique as a method to transfer calibration parameters among multiple AWCC systems without the need for multiple sets of physical reference standards. For 93\% HEU metal in solid disk and pieces form, the largest absolute mass error was $6.08 \%$ while the average absolute mass error was less than $3 \%$, well within control limits of the MPC\&A program in place at ANLW. It is important to note, however, that the third degree polynomial used to characterize the AWCC system response for HEU assay is an empirical estimation of the system response and does not correspond to the physical interactions occurring within the sample. As a result it is not possible to extrapolate the calibration curves beyond the mass range from which they were developed. In the case of the HEU pieces measurements analyzed during this project, it was possible to apply the cross calibration technique over the mass range of 2700-4000g, but not above it, even though ANLW routinely measures items of HEU pieces with larger mass. The mass range of the standards used to develop the calibration parameters limits the applicable mass range of the cross calibration technique as implemented in this report. The addition of higher mass standards during the development of calibration parameters is a direct method that could be utilized to extend the mass ranges. Since this requires the development of additional standards, it is not very cost-effective, however. Modeling the AWCC system with Monte Carlo simulation is being investigated as a low cost method able to add flexibility to the implementation of the cross calibration technique, both as a method to extend calibration parameters beyond the masses of current standards and also to adjust reference calibration parameters to materials with unique geometries and compositions.

The results of the HEU disk and pieces measurements performed with the ANLW AWCC as well as the work performed at MEPhI [2,3] suggest that a properly implemented cross calibration program could be an effective method for HEU calibration parameters to be shared among the AWCC systems currently in Russia. Such a program would reduce the number of physical standards that must be produced and allowing the expedient development of calibration parameters. Prior to shipment, many of the AWCC 
systems currently in Russia were referenced to the AWCC-Gold system at LANL and the AmLi source strength for each system determined. Results of these measurements are included in Appendix II and III, respectively. These reference measurements allow the implementation of a cross calibration program for the Russian AWCC systems similar to that outlined in this report and specified in the draft procedure included in Appendix I. The systems that did not perform reference measurements at LANL can easily be referenced to the other systems through the measurement of suitable HEU standards in Russia.

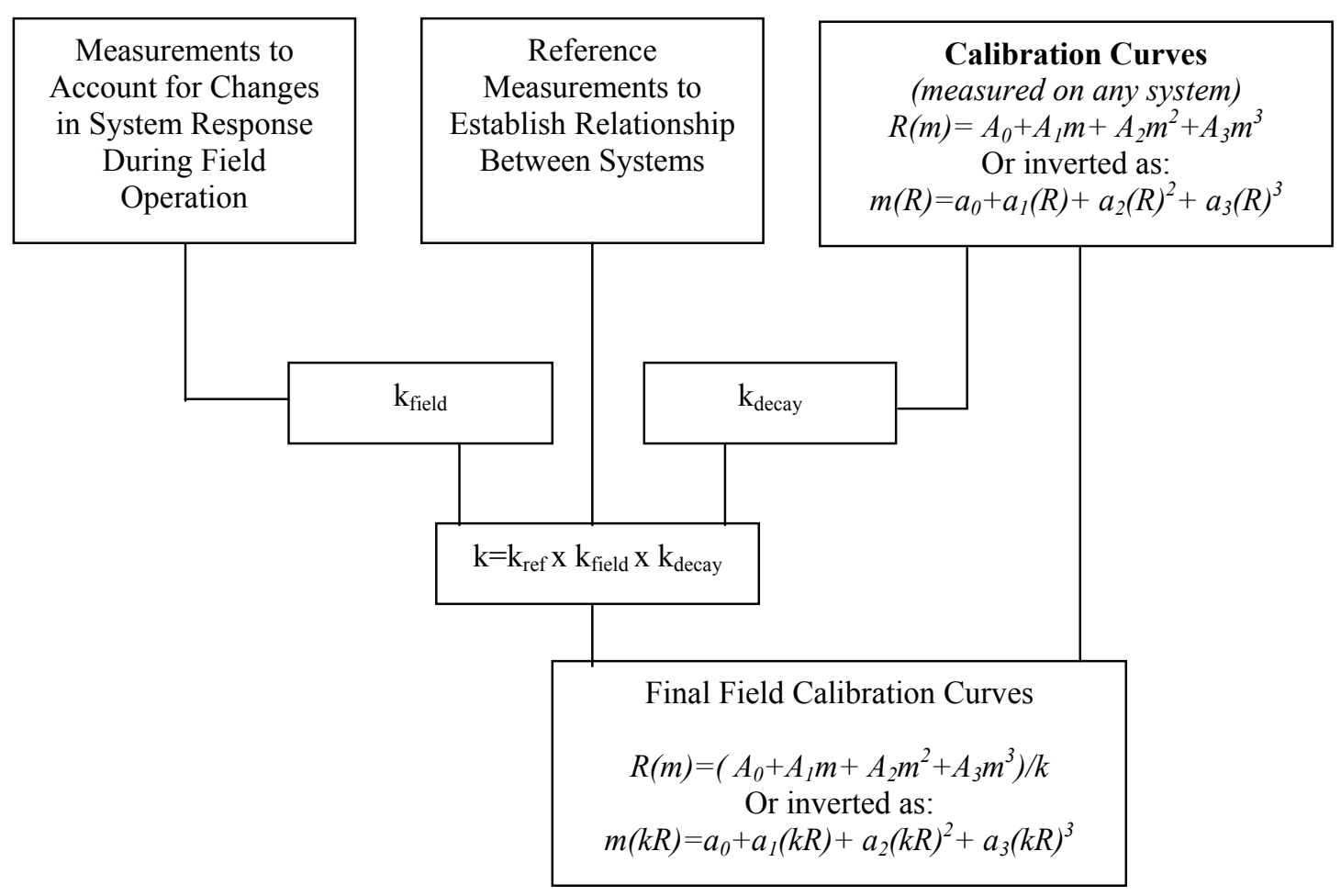

Figure 6. Cross calibration flow chart employing AmLi sources for field system correction

A generalized flow chart for the cross calibration technique is shown in Figure 6.

Necessary for the technique are: 1) well characterized calibration curves measured on (or easily transferred to) a reference system; 2) a method to relate the reference system response to a field system; and 3) a method to account for electronic changes in the field system during measurement campaigns. The specific technique utilized for this report is shown in Figure 7 and relies upon calibration parameters measured on or transferred to the AWCC-Gold system, reference measurements of the C-20-8 standard and 
measurements of the change in net singles rate to account for electronic system changes. Many possible permutations of the cross-calibration program could be applied in Russia, though the technique utilized in this report appears to be well suited to their needs, requiring only the LANL cross calibration reference measurement data and periodic measurement of the net singles rate. Any AWCC involved in the program can be used as the effective reference system, creating a decentralized calibration program without the need for the shipment of sources or standards.

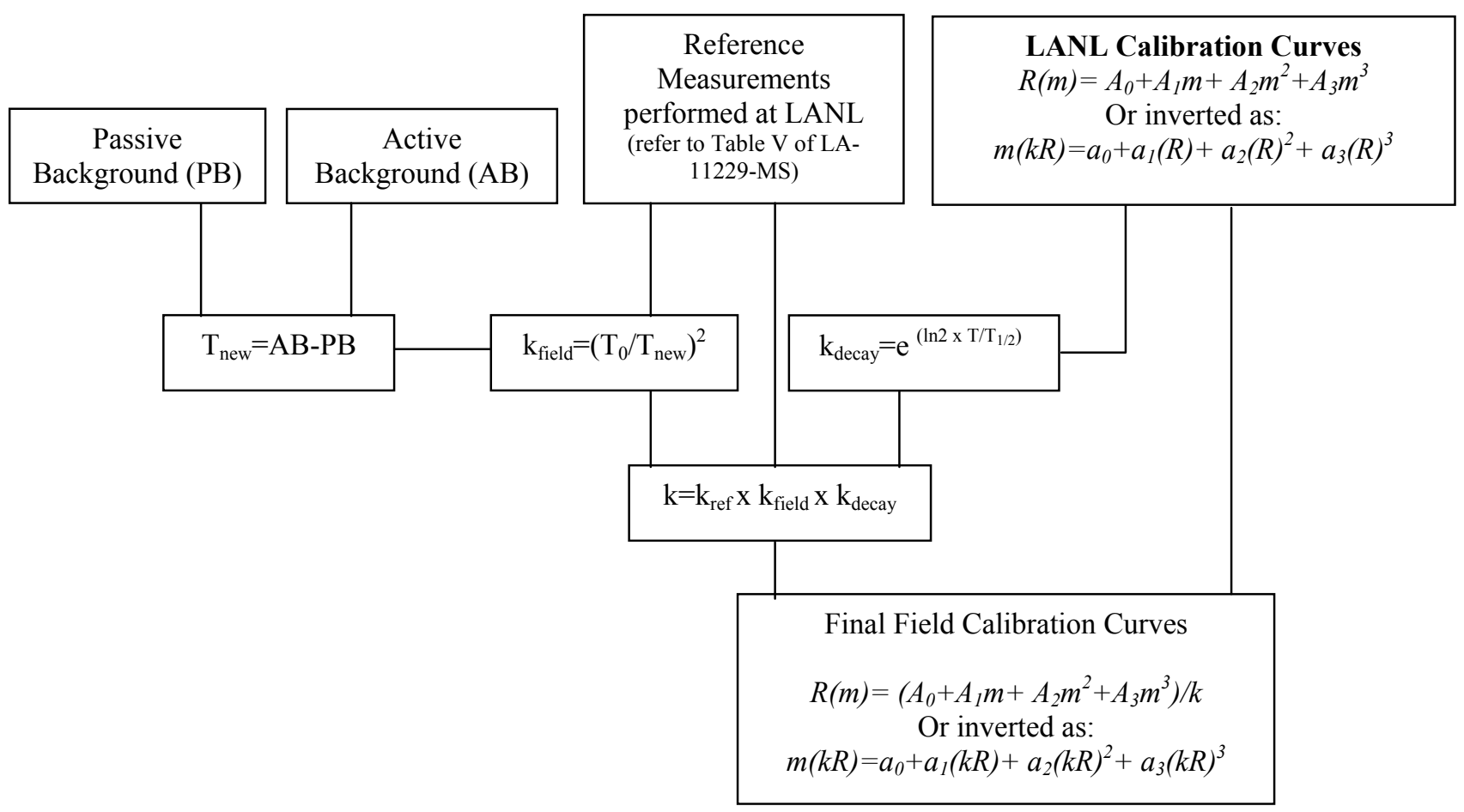

Figure 7. Cross calibration flow chart employing AmLi sources for field system correction

In general, the cross calibration technique can be altered to employ various neutron sources and physical standards to provide reference and field system calibration. The method is limited by two considerations: accuracy and logistical feasibility. The AWCC calibration program developed by LANL balances these two characteristics by using a single reference standard to limit the number of standards that must be developed, and a Cf-252 source which produces neutrons with a spectrum similar to that seen during U235 fission. An example flowchart of this preferred procedure is included in Figure 8. For the ANLW calibration discussed in this report, it was not logistically feasible to ship the standard Cf-252 source and no unique source was purchased for the system. The use of 
the net AmLi background measurement to adjust for changes in electronic response was a necessary compromise in calibration accuracy under the circumstances.

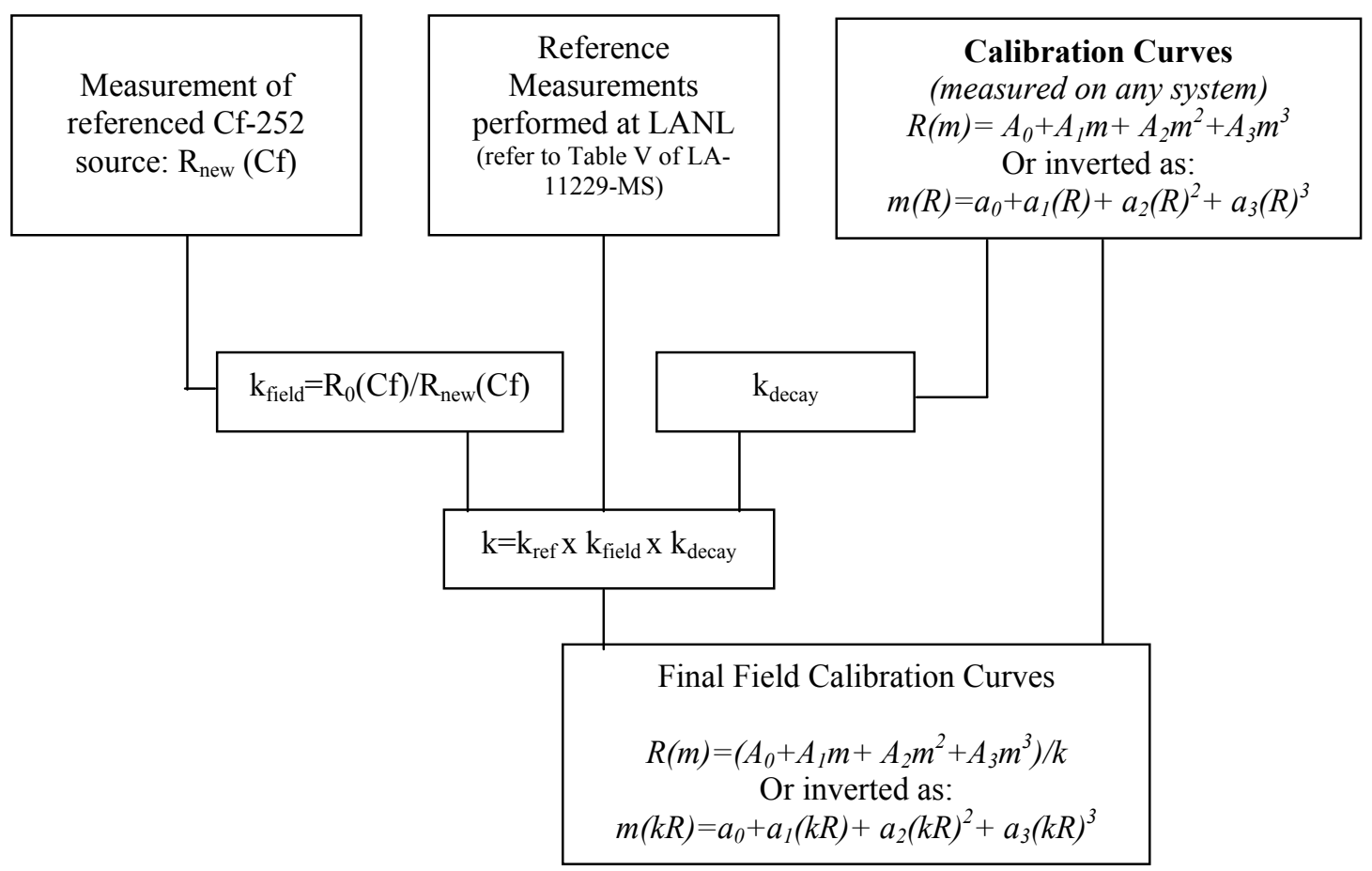

Figure 8. Alternative calibration technique utilizing Cf-252 source to determine field correction, LANL reference measurements to relate systems and predetermined calibration curves

Similarly, the reference correction term can also be determined using alternative methods. Since the response of the system will be highly dependent upon the AmLi source strength and detector efficiency, it is possible to use the ratio of absolute AmLi source strength and Cf-252 measurements to determine the reference correction. Because of differences in AmLi source geometry, specifically the depth of the americium oxide, this method does not predict the relationship between the reference and field system as accurately as the use of physical reference standards[2], but does make it unnecessary to ship systems or sources to establish reference baselines as long as the source strength is known. Since the AmLi source strength for each Russian system was measured during the LANL reference measurements, it is possible to estimate the accuracy of this method by comparing the normalization term determined using the physical standards and that 
determined by source strength combined with detection efficiency determined by measurements of the AmLi and standard Cf-252 sources.

Table 7. Summary of $k_{\text {ref }}$ determined from AmLi and Cf-252 source and C-20-8 standard measurements

\begin{tabular}{|c|c|c|c|c|c|c|c|}
\hline \multirow[b]{2}{*}{ Facility } & \multirow{2}{*}{$\frac{\text { Ro (Gold)/Ro(XX) }}{\text { kref }}$} & \multirow{2}{*}{$\frac{A m L i_{\text {gold }} / A m L i_{x x}}{k_{A m L i}}$} & \multirow{2}{*}{$\frac{\mathbf{R}_{\mathrm{Cf}(\text { Gold })} / \mathbf{R o}_{\mathrm{Cf}(\mathrm{XX})}}{\mathrm{k}_{\mathrm{Cf}}}$} & \multirow{2}{*}{$\frac{\mathbf{k}_{\text {AmLi }} \mathbf{x} \mathbf{k}_{\mathrm{Cf}}}{\mathrm{kref}_{\mathrm{AmLi} \times \mathrm{Cf}}}$} & \multirow{2}{*}{$\frac{\text { kref Ratio }}{\text { kref/kref }_{\text {AmLi x Cf }}}$} & \multicolumn{2}{|c|}{ kref Error } \\
\hline & & & & & & $\begin{array}{c}\text { (kref-kref } \\
\text { /kref }\end{array}$ & $\begin{array}{c}\text { Bias } \\
\text { adjusted }\end{array}$ \\
\hline LANL & 1.000 & 1.000 & 1.000 & 1.000 & 1.000 & $0.00 \%$ & $-7.90 \%$ \\
\hline Novosibirsk-NCCP & 0.959 & 0.920 & 1.009 & 0.928 & 1.033 & $3.20 \%$ & $-4.70 \%$ \\
\hline VNIITF & 1.026 & 0.929 & 1.010 & 0.939 & 1.093 & $8.49 \%$ & $0.59 \%$ \\
\hline Kurchatov (1) & 0.909 & 0.796 & 1.000 & 0.796 & 1.142 & $12.42 \%$ & $4.52 \%$ \\
\hline Kurchatov (2) & 0.972 & 0.823 & 1.047 & 0.862 & 1.128 & $11.37 \%$ & $3.47 \%$ \\
\hline Elektrostal & 0.899 & 0.828 & 1.028 & 0.851 & 1.056 & $5.31 \%$ & $-2.59 \%$ \\
\hline Mayak (1) & 1.117 & 1.034 & 0.998 & 1.032 & 1.082 & $7.59 \%$ & $-0.31 \%$ \\
\hline Mayak (2) & 1.086 & 0.990 & 1.003 & 0.993 & 1.094 & $8.59 \%$ & $0.70 \%$ \\
\hline GAN (1) - Seversk & 0.944 & 0.857 & 0.989 & 0.848 & 1.113 & $10.14 \%$ & $2.24 \%$ \\
\hline GAN(2) - K-25 & 0.850 & 0.836 & 0.949 & 0.793 & 1.072 & $6.71 \%$ & $-1.19 \%$ \\
\hline GAN (3)-Sverdlovsk44 & 0.958 & 0.850 & 0.997 & 0.847 & 1.131 & $11.61 \%$ & $3.71 \%$ \\
\hline GAN (4) - Kurchatov & 0.906 & 0.819 & 0.993 & 0.813 & 1.114 & $10.26 \%$ & $2.36 \%$ \\
\hline GAN (5) - RIAR & 0.924 & 0.797 & 1.025 & 0.817 & 1.130 & $11.54 \%$ & $3.64 \%$ \\
\hline Kurchatov & 0.985 & 1.132 & - & - & - & - & - \\
\hline Moscow Inorganics & 1.106 & 0.928 & 1.095 & 1.017 & 1.088 & $8.08 \%$ & $0.18 \%$ \\
\hline Moscow Automatics & 1.073 & 0.933 & 1.207 & 1.126 & 0.953 & $-4.98 \%$ & $-12.88 \%$ \\
\hline T.0.10 & 1.070 & 0.956 & 1.028 & 0.983 & 1.089 & $8.15 \%$ & $0.25 \%$ \\
\hline Argonne-West (ANLW) & 1.079 & 1.164 & 1.079 & 1.256 & 0.859 & $-16.42 \%$ & $-24.32 \%$ \\
\hline
\end{tabular}

Table 7 is a summary of $k_{\text {ref }}$ determined from measurements of the HEU physical standard as well as by the normalizing the AmLi and Cf-252 measurements. Averaging the relative error found in the Russian systems reveals a bias of $7.9 \% \pm 4.36 \%$ while that for the ANLW AWCC is nearly $-25 \%$, indicating that it may not be possible to utilize this alternate technique on all systems, most likely due to differences in the fabrication of end caps and AmLi sources. Applying the $7.9 \%$ bias to the $k_{\text {ref }}$ terms determined with AmLi and Cf-252 sources on the Russian systems produces a $k_{r e f}$ within $5 \%$ of that determined by measuring reference standards. It is clear that this method could be used as an estimation of $k_{\text {ref }}$ but that further investigation into the source of system bias would be needed. In general, the use of appropriate reference standards provides the most accurate normalization. As discussed in [4], $k_{r e f}$ can be expected to change 5-10\% depending on sample enrichment and composition, limiting the applicability of assigning a single kref 
to a system without some type of sample correction. Figure 9 is a plot of the deviation in $k_{\text {ref }}$ determined by the AmLi and Cf-252 source measurements for each AWCC system.

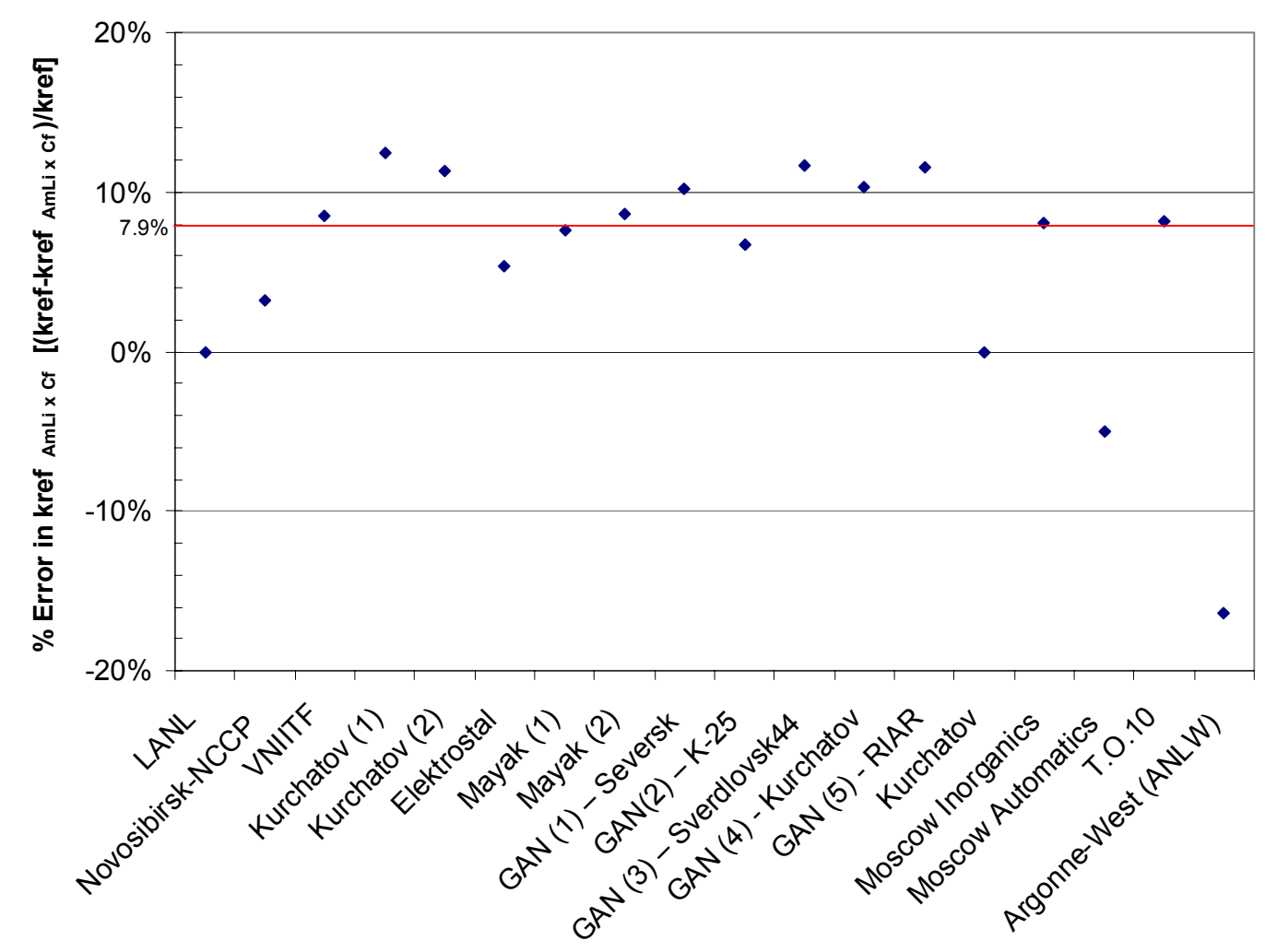

Figure 9. Error in $k_{\text {ref }}$ determined by AmLi and Cf-252 source measurements relative to reference measurements

\section{Conclusion}

The AWCC cross-calibration procedure developed by LANL was successfully demonstrated on the ANLW AWCC for 93\% HEU metal items. Samples items of metal disks and heel pieces were measured using adjusted calibration curves with an average absolute mass error of less than 3\% from declared masses over applicable mass ranges. Calibration curves were transferred among three systems, demonstrating the flexibility of the technique. The measurements verify that facilities can accurately use high precision AWCC calibration curves in combination with a cross calibration program to measure HEU metal disks and pieces without requiring the development of costly standards. The cross calibration program outlined in this publication appears to be a cost effective means of determining calibration parameters for the AWCC systems. 
Historically, ANLW has relied upon chemical analysis of heel samples and the detailed knowledge of sample history to develop calibration curves with large mass ranges and high accuracy. While the HEU pieces cross calibration curve developed during this project calculates assay mass within ANLW quality control standards over the 2700$4000 \mathrm{~g}$ fissile mass range, it cannot be accurately applied beyond this mass range due to the limited mass range of the standards used to determine the curve. Modeling the AWCC system with Monte Carlo simulation is being investigated as a cost effective method to add flexibility to the implementation technique, both as a method to extend calibration parameters beyond the masses of current standards and also to transfer reference calibration curves to materials with unique geometries and compositions. ANLW has been involved in the manufacturing of metal fuels with varying enrichment levels for over 30 years and these and other fissile materials are currently stored on site. While AWCC systems were not used in the accounting of these materials, the development of AWCC calibration curves for these materials using cross calibration techniques in conjunction with modeling is currently being investigated.

The AWCC cross calibration program allows facilities involved to use these and other calibration curves without the need to develop or store collections of calibration standards, reducing the time and cost involved in maintaining a flexible MPC\&A program. These characteristics make the cross calibration technique extremely applicable to MPC\&A programs that find themselves with a shortage of NDA physical standards, such as is the case in Russia. Implementation of the cross calibration technique in Russia appears to be a cost effective method to determine calibration parameters. The reference measurements performed at LANL prior to shipment to Russia should aid greatly in the implementation of such a program. Systems that did not perform these measurements can be included in the program through the measurement of suitable reference standards in Russia, or through the use of alternative reference normalization determination, as discussed in this report. 


\section{References}

[1] H. O. Menlove and J. E. Stewart, "A New Method of Calibration and Normalization for Neutron Detector families," Los Alamos National Laboratory report LA-11229-MS (ISPO-287) (April 1988).

[2] V. Nikolaev, I. Prochin, V. Smirnov, N. Ensslin and L. Carrillo, "Uranium CrossCalibration Measurements Using an Active Well Coincidence Counter," Los Alamos National Laboratory report LA-UR-98-2750 (July 1998).

[3] V. Nikolaev, I. Prochin, V. Smirnov, N. Ensslin and L. Carrillo, "Final Results of Cross-Calibration Measurements at MEPhI," Los Alamos National Laboratory report LA-UR-99-3474 (July 1999).

[4] A.V. Mozhayev, V.S. Fedorov, V.G. Nikolaev, W.D. Ruhter, N. Ensslin, R.S. Marshall and H.W. Hoida, "The Active Well Coincidence Counter (AWCC) Cross Calibration Workshop at the Institute of Physics and Power Engineering," Proceedings of INMM $41^{\text {st }}$ Annual Meeting (Proc. CD-ROM, 2001). 


\section{Appendix I. Draft Field Guide for Assay of HEU Metal Samples using Cross Calibration}

\section{Scope}

This field guide is intended to provide guidance on performing assay measurements of HEU samples using an AWCC and the cross calibration technique developed by LANL. It assumes that measurements of reference standards have previously occurred and that calibration curve coefficients appropriate to the sample(s) to be assayed are available.

\section{Background}

Necessary for the technique are: 1) well characterized calibration curves measured on (or easily transferred to) a reference system; 2) a method to relate the reference system response to a field system; and 3) a method to account for electronic changes in the field system during measurement campaigns. In this report, the calibration curves were measured on or transferred to the AWCC-Gold system. Measurements of reference HEU disk C-20-8 were used to relate the response of the reference and field systems, and the net active background (active background minus passive background) singles rate was used to account for electronic changes in the field system. 


\section{Procedure}

\section{Setup}

During setup of the AWCC in a new location, care must be taken to place the system in a location with low neutron coincidence background levels, away from fissionable materials or extremely active neutron sources. More importantly, the AWCC unit should not be placed in a location with unstable coincidence rates. Changes in background neutron coincidence rates during measurements will introduce bias to assay results. It is essential that operators ensure the shift register has the proper setup/measurement parameters. Common parameters are shown in Table 6. This procedure is based on the AWCC cross-referencing procedure for HEU metal disks, provided by the safeguards science and technology group at LANL during the cross calibration study.

1. Turn on shift register main power and high voltage

2. Ensure the AWCC is in Mode-1 configuration and that the $\mathrm{Cd}$ liner and $\mathrm{Ni}$ collar are in place

3. Verify the high voltage setting on the shift register is correct

4. Start the shift register software and ensure the following settings are in the Setup/Measurement Parameters, located under the Maintain heading (Maintain mode is turned on by selecting Maintain under the View heading)

Table 8. Standard JSR-12 operating parameters

\begin{tabular}{|c|c|}
\hline Shift Register Type & JSR-12 \\
\hline Shift Register serial port & COM1 \\
\hline Pre-delay $(\mu \mathrm{s})$ & 4.5 \\
\hline Gate Length $(\mu \mathrm{s})$ & 64 \\
\hline High Voltage $(\mathrm{V})$ & 1700 \\
\hline Die Away Time $(\mu \mathrm{s})$ & 50 \\
\hline Deadtime Coefficients A, B, C & $0,0,0$ \\
\hline Other Parameters & Not Used \\
\hline
\end{tabular}




\section{Background Measurements}

Once the AWCC is in the measurement location, the active and passive background total and coincidence rates should be measured and recorded. The passive background rate is measured with the AmLi sources removed from the system while the active background coincidence rate is measured with the AmLi sources in place. If a $\mathrm{Cf}$ source is present, it should be measured to correct for electronic variations.

\section{Passive Background}

1. Remove AmLi sources from the system by removing the sources and placing the end plugs back onto the system

2. Ensure the cavity is empty

3. Set the Error Calculation Method under the Maintain heading to theoretical

4. Acquire one 1000 second background measurement

5. Record the passive background rate $(\mathrm{PB})$ and standard deviation $\left(\sigma_{\mathrm{PB}}\right)$

\section{Active Background}

1. Place AmLi sources (properly oriented) in the end plugs and place end plugs onto the system

2. Ensure the cavity is empty

3. Set the Error Calculation Method under the Maintain heading to theoretical

4. Acquire one 300 second background measurement

5. Record the active background rate $(\mathrm{AB})$ and standard deviation $\left(\sigma_{\mathrm{AB}}\right)$

\section{Cf-252 Normalization}

In cases where a Cf-252 referenced to the standard CF-5 LANL source during system calibration is available, the system response should also be measured.

1. Remove AmLi sources from the system by removing the end plugs, pointing the source ends away from the system; do not remove sources from plugs

2. Place Cf-252 source in system cavity at a height of $10 \mathrm{~cm}$

3. Set method of calculating statistics to Sample Standard

4. Acquire data for 50 cycles of 100 seconds

5. Remove Cf-252 source and secure away from system

6. Record singles and doubles rate as well as associated standard deviations 


\section{Curve Normalization}

Based on the total count rate determined in the measurement location and the calibration correction terms determined during reference measurements, the final field correction term can be determined and applied to appropriate calibration curve equations.

1. Calculate $T_{\text {new }}=A B-P B$

2. $k_{\text {field }}=\left(T o / T_{\text {new }}\right)^{2}$ (refer to LA-11229-MS for field system $T o$ ) note: in situations where a Cf-252 source referenced to the standard Cf source is available, the ratio of the calibration and current system response $(R o(C f-x x) / R n e w(C f-x x))$ should be used for $k_{f i e l d}$.

3. Based on material to be assayed, determine the reference system the calibration curve was measured on

4. Obtain $k_{r e f}$ correction term appropriate to the material type and field/reference system (refer to LA-11229-MS)

5. Account for AmLi source decay occurring since determination of calibration parameters using $k_{\text {decay }}=e^{(0.0016 / y r \times T)}$ where $T$ is the number of years from the measurement date to the date of calibration parameter determination

6. Final correction term $k=k_{\text {field }} x k_{\text {ref }} x k_{\text {decay }}$

7. Apply correction to calibration curve, as shown below.

$$
\begin{gathered}
R(m)=\left(A_{0}+A_{1} m+A_{2} m^{2}+A_{3} m^{3}\right) / k \\
\text { Or inverted as: } \\
m(k R)=a_{0}+a_{1}(k R)+a_{2}(k R)^{2}+a_{3}(k R)^{3} \\
\text { for } x=0,1,2,3 \\
A_{\text {xnew }}=A_{x} / k \\
a_{\text {xnew }}=a_{x}\left(k^{x}\right)
\end{gathered}
$$




\section{Appendix II. Russian AWCC Calibration Cross-Reference Data for HEU Metal Disks (Mode-1)}

Table 9. AWCC cross reference data for HEU metal

\begin{tabular}{|c|c|c|c|c|c|c|c|}
\hline \multicolumn{8}{|c|}{$\begin{array}{c}\text { Russian AWCC Calibration Cross-Reference Data for HEU Metal Disks (Mode-1) } \\
\text { (Updated July 16, 2002) }\end{array}$} \\
\hline Facility & Detector ID & $\begin{array}{c}\text { AmLi } \\
\text { (Top/Bottom) }\end{array}$ & $\begin{array}{c}T_{o} \text { (empty) } \\
\text { (cps) } \\
\text { (y-m-d) } \\
\end{array}$ & $\begin{array}{l}\text { Cf } \\
\text { ID }\end{array}$ & $\begin{array}{c}R_{o}(\mathrm{Cf})^{b} \\
\quad(\mathrm{cps})\end{array}$ & $\begin{array}{c}R_{o}(\mathrm{XX})^{c} \\
(\mathrm{cps})\end{array}$ & $\frac{R o(\text { Gold })}{R_{o}(\mathrm{XX})}$ \\
\hline LANL & $\begin{array}{l}\text { Gold AWCC, } \\
\text { SN300 }\end{array}$ & MRC116/MRC115 & $\begin{array}{c}7128 \\
(96-03-21)\end{array}$ & CF-5 & 3052 & 41.66 & 1.000 \\
\hline $\begin{array}{l}\text { Novosibirsk- } \\
\quad \text { NCCP }\end{array}$ & $\begin{array}{c}\text { Canberra, SN } \\
07989940\end{array}$ & N451/N452 & $\begin{array}{c}6271 \\
(98-10-27)\end{array}$ & CF-5 & 3025 & 43.46 & 0.959 \\
\hline VNIITF & $\begin{array}{l}\text { Canberra, } \\
\text { SN11975292 }\end{array}$ & N415/N440 & $\begin{array}{c}6306 \\
(98-05-13)\end{array}$ & CF-5 & 3021 & 40.61 & 1.026 \\
\hline Kurchatov (1) & $\begin{array}{l}\text { Canberra, } \\
\text { SN12975731 }\end{array}$ & N431/N432 & $\begin{array}{c}7468 \\
(98-07-17)\end{array}$ & CF-5 & 3051 & 45.85 & 0.909 \\
\hline Kurchatov (2) & $\begin{array}{l}\text { Canberra, SN } \\
1975294\end{array}$ & N424/N405 & $\begin{array}{c}6790 \\
(98-03-30)\end{array}$ & $\mathrm{CF}-5$ & 2916 & 42.88 & 0.972 \\
\hline Elektrostal & $\begin{array}{l}\text { Canberra, } \\
\text { SN11975293 }\end{array}$ & N430/N414 & $\begin{array}{c}7017 \\
(98-07-31)\end{array}$ & CF-5 & 2970 & 46.34 & 0.899 \\
\hline Mayak (1) & $\begin{array}{l}\text { Canberra, SN } \\
02987113\end{array}$ & N429/N438 & $\begin{array}{c}5840 \\
(98-06-02)\end{array}$ & CF-5 & 3057 & 37.29 & 1.117 \\
\hline Mayak (2) & $\begin{array}{c}\text { Canberra, SN } \\
02987112\end{array}$ & N435/N439 & $\begin{array}{c}5985 \\
(98-06-03)\end{array}$ & CF-5 & 3044 & 38.35 & 1.086 \\
\hline $\begin{array}{l}\text { GAN (1) - } \\
\text { Seversk }\end{array}$ & $\begin{array}{c}\text { Canberra, SN } \\
10974271\end{array}$ & N416/N422 & $\begin{array}{c}6851 \\
(98-04-02)\end{array}$ & CF-5 & 3085 & 44.15 & 0.944 \\
\hline GAN(2) - K-25 & $\begin{array}{c}\text { Canberra, } \\
\text { SN10974270 }\end{array}$ & N412/N402 & $\begin{array}{c}7118 \\
(98-04-13)\end{array}$ & $\mathrm{CF}-5$ & 3217 & 49.00 & 0.850 \\
\hline $\begin{array}{c}\text { GAN (3) - } \\
\text { Sverdlovsk44 }\end{array}$ & $\begin{array}{c}\text { Canberra, } \\
\text { SN10974881 }\end{array}$ & N406/N407 & $\begin{array}{c}6955 \\
(98-04-01)\end{array}$ & CF-5 & 3062 & 43.47 & 0.958 \\
\hline $\begin{array}{l}\text { GAN (4) - } \\
\text { Kurchatov }\end{array}$ & $\begin{array}{c}\text { Canberra, SN } \\
10974882\end{array}$ & N421/N419 & $\begin{array}{c}7322 \\
(98-04-01)\end{array}$ & CF-5 & 3075 & 45.99 & 0.906 \\
\hline GAN (5) - RIAR & $\begin{array}{c}\text { Canberra, SN } \\
10974883\end{array}$ & N420/N413 & $\begin{array}{c}7437 \\
(98-04-01)\end{array}$ & CF-5 & 2977 & 45.08 & 0.924 \\
\hline Kurchatov & Aquila, SN AQ002 & N158/N159 & - & $\mathrm{CF}-5$ & - & 42.31 & 0.985 \\
\hline $\begin{array}{l}\text { Moscow } \\
\text { Inorganics }\end{array}$ & Aquila, SN AQ004 & N173/N174 & $\begin{array}{c}5438 \\
(96-08-02)\end{array}$ & CF-5 & 2787 & 37.66 & 1.106 \\
\hline $\begin{array}{l}\text { Moscow } \\
\text { Automatics }\end{array}$ & Aquila, SN AQ005 & N177/N178 & $\begin{array}{c}5469 \\
(97-04-24)\end{array}$ & CF-5 & 2528 & 38.84 & 1.073 \\
\hline RIAR & $\begin{array}{c}\text { Canberra, SN } \\
1979387\end{array}$ & N185/N186 & $?$ & CF-5 & $?$ & $?$ & $?$ \\
\hline
\end{tabular}




\begin{tabular}{|c|c|c|c|c|c|c|c|}
\hline \multicolumn{8}{|c|}{$\begin{array}{c}\text { Russian AWCC Calibration Cross-Reference Data for HEU Metal Disks (Mode-1) } \\
\text { (Updated July 16, 2002) }\end{array}$} \\
\hline Facility & Detector ID & $\begin{array}{c}\text { AmLi } \\
\text { (Top/Bottom) }\end{array}$ & $\begin{array}{c}T_{o} \text { (empty) }^{a} \\
\quad(\mathrm{cps}) \\
(\mathrm{y}-\mathrm{m}-\mathrm{d})\end{array}$ & $\begin{array}{l}\mathrm{Cf} \\
\mathrm{ID}\end{array}$ & $\begin{array}{c}R_{o}(\mathrm{Cf})^{b} \\
\quad(\mathrm{cps})\end{array}$ & $\begin{array}{l}\operatorname{Ro}_{o}(\mathrm{XX})^{c} \\
\quad(\mathrm{cps})\end{array}$ & $\frac{R o(\text { Gold })}{R_{o}(\mathrm{XX})}$ \\
\hline IPPE/BFS & (painted blue) & $\mathrm{C} 471 / \mathrm{C} 473$ & $?$ & $?$ & $?$ & $?$ & $?$ \\
\hline IPPE/CSF & Canberra & N447/N448 & $?$ & $?$ & $?$ & $?$ & $?$ \\
\hline IPPE/RMTC & Canberra & $?$ & $?$ & $?$ & $?$ & $?$ & $?$ \\
\hline MEPhI (1) & $\begin{array}{l}\text { Canberra, SN } \\
11975291\end{array}$ & N410/N411 & $\begin{array}{c}6711 \\
(98-02-04)\end{array}$ & CF-5 & 2902 & - & - \\
\hline Sverdlovsk 45 & $?$ & $?$ & $?$ & $?$ & $?$ & $?$ & $?$ \\
\hline $\begin{array}{l}\text { Krylov ship } \\
\text { building research } \\
\text { institute }\end{array}$ & - & N441/N442 & - & - & - & - & - \\
\hline T.O.10 (?) & $\begin{array}{l}\text { Aquila, SN C97- } \\
\quad 004\end{array}$ & N433/N434 & $\begin{array}{c}5267 \\
(98-04-23)\end{array}$ & CF-5 & 2969 & 38.93 & 1.070 \\
\hline $\begin{array}{l}\text { Argonne-West } \\
\text { (ANLW) }\end{array}$ & Canberra, SN & N059/N060 & 5645 & CF-5 & 2829 & 38.60 & 1.079 \\
\hline
\end{tabular}

$a_{\text {Mode-1 }}$ with the lids of both AmLi sources pointed away from the sample cavity.

$b_{\text {The }}$ Ro (Cf) was measured with the end plugs in Mode- 1 , and the ${ }^{252} \mathrm{Cf}$ source $10 \mathrm{~cm}$ above the bottom (centered). Ro (Cf) is corrected for Cf- 252 decay back to $96 / 03 / 21$ using a decay constant of $\lambda=0.26196 \mathrm{y}^{-1}$.

${ }^{c}$ The Ro(XX) is corrected for AmLi source decay back to 96/03/21 using a decay constant of $\lambda=0.0016 \mathrm{y}^{-1}$.

The symbol '-' indicates the measurement was not made

The symbol '?' indicates the data is missing and it is not known whether the measurement was made 


\section{Appendix III. AmLi Source Yield Comparison}

Table 10. AmLi source yield comparison

\begin{tabular}{|c|c|c|}
\hline \multicolumn{3}{|c|}{$\begin{array}{c}\text { AmLi Source Yield Comparison } \\
\text { (Updated June 18, 2002) }\end{array}$} \\
\hline Source No. & $\begin{array}{l}\text { Yield Relative to } \\
\text { MRC- } 95^{\text {a }}\end{array}$ & Location \\
\hline C-471 & 1.153 & Obninsk \\
\hline C-473 & 1.116 & Obninsk \\
\hline MRC-95 & 1.000 & Los Alamos \\
\hline $\mathrm{N}-059$ & 1.112 & Argonne -West \\
\hline $\mathrm{N}-060$ & 1.114 & Argonne -West \\
\hline $\mathrm{N}-158$ & 1.147 & Kurchatov \\
\hline N-159 & 1.142 & Kurchatov \\
\hline $\mathrm{N}-173$ & 1.397 & Moscow/Inorganics \\
\hline $\mathrm{N}-174$ & 1.395 & Moscow/Inorganics \\
\hline N-177 & 1.400 & Moscow/Automatics \\
\hline $\mathrm{N}-178$ & 1.378 & Moscow/Automatics \\
\hline N-179 & 1.340 & Sosny-Belarus \\
\hline $\mathrm{N}-180$ & 1.338 & Sosny-Belarus \\
\hline $\mathrm{N}-185$ & 1.575 & Dimitrovgrad \\
\hline $\mathrm{N}-186$ & 1.558 & Dimitrovgrad \\
\hline $\mathrm{N}-402$ & 1.550 & GAN \\
\hline $\mathrm{N}-405$ & 1.570 & Kurchatov \\
\hline $\mathrm{N}-406$ & 1.533 & GAN \\
\hline $\mathrm{N}-407$ & 1.518 & GAN \\
\hline $\mathrm{N}-410$ & 1.532 & MEPhI \\
\hline N-411 & 1.536 & MEPhI \\
\hline $\mathrm{N}-412$ & 1.551 & GAN \\
\hline $\mathrm{N}-413$ & 1.632 & GAN \\
\hline $\mathrm{N}-414$ & 1.560 & Elektrostal \\
\hline $\mathrm{N}-415$ & 1.444 & VNIITF \\
\hline $\mathrm{N}-416$ & 1.506 & GAN \\
\hline $\mathrm{N}-419$ & 1.580 & GAN \\
\hline $\mathrm{N}-420$ & 1.619 & GAN \\
\hline $\mathrm{N}-421$ & 1.584 & GAN \\
\hline $\mathrm{N}-422$ & 1.517 & GAN \\
\hline $\mathrm{N}-424$ & 1.579 & Kurchatov \\
\hline
\end{tabular}




\begin{tabular}{|c|c|l|}
\hline \multicolumn{3}{|c|}{$\begin{array}{c}\text { AmLi Source Yield Comparison } \\
\text { (Updated June 18, 2002) }\end{array}$} \\
\hline Source No. & $\begin{array}{c}\text { Yield Relative to } \\
\text { MRC-95 }\end{array}$ & Location \\
\hline \hline N-425 & 3.164 & GAN (Collar-1) \\
\hline N-426 & 3.240 & GAN (Collar-2) \\
\hline N-429 & 1.288 & Mayak \\
\hline N-430 & 1.569 & Elektrostal \\
\hline N-431 & 1.590 & Kurchatov (at LANL 25Jun02) \\
\hline N-432 & 1.667 & Kurchatov (at LANL 25Jun02) \\
\hline N-433 & 1.345 & T.O.10 \\
\hline N-434 & 1.366 & T.O.10 \\
\hline 0N-435 & 1.303 & Mayak \\
\hline N-436 & 1.337 & (at LANL 25Jun02) \\
\hline N-437 & 1.333 & (at LANL 25Jun02) \\
\hline N-438 & 1.219 & Mayak \\
\hline N-439 & 1.315 & Mayak \\
\hline N-440 & 1.345 & VNIITF \\
\hline N-441 & 1.418 & Krylov \\
\hline N-442 & 1.347 & Krylov \\
\hline N-451 & 1.421 & Novosibirsk \\
\hline N-452 & 1.396 & Novosibirsk \\
\hline
\end{tabular}

${ }^{\mathrm{a}}$ An updated absolute calibration was performed on MRC-95. The resulting yield was $3.35 \times 10^{4} \mathrm{n} / \mathrm{s}$ on $99-\mathrm{Apr}-22$. 